Aus dem I. Anatomischen Institut der Universität Budapest.

Vorstand: Prof. Dr. M. v. Lenhossék.

\title{
Untersuchungen über den Glaskörper der Amphibien und Reptilien.
}

\author{
Von
}

Albert Szent-Györgyi in Budapest.

\author{
Hierzu Tafel XIV-XVIII und 6 Textfiguren.
}

Wahrend die Genese des Glaskörpers bei den verschiedenen Wirbeltieren im letzten Jahrzehnt Gegenstand zahlreicher Untersuchungen und Diskussionen gewesen ist, ist der Bau des fertigen Glaskörpers und besonders die vergleichende Histologie und Histotopographie der Glaskörperfibrillen weniger berücksichtigt worden. Selbst über die Frage, ob dieses fibrillăre Gerüstwerk überhaupt typische Verschiedenheiten im Auge verschiedener Wirbeltiere zeige, waren wir bisher nicht genügend unterrichtet.

Die Ursache, warum diese Seite der Forschung, die ja sozusagen ein ganzes Kapitel der vergleichenden Histologie des Auges ausmacht, bisher so gut wie ganz unbeachtet geblieben ist, liegt an den technischen Schwierigkeiten des Gegenstandes. Die bisherigen histologischen Methoden sind nicht geeignet, den Glaskörper in situ, ohne Schrumpfungen und Verzerrungen zur Darstellung zu bringen.

Vit einer besonderen, von der bisherigen ganz abweichenden Methodik (Silberimprăgnation, Gelatinedurchtränkung, Gefrierschnitte), die ich an anderer Stelle gleichzeitig mit dieser Arbeit veröffentliche, ist es mir gelungen, dieser Schwierigkeiten Herr zu werden und Präparate aus dem Auge verschiedener Wirbeltiere $z u$ erhalten, die den Glaskörper in seiner natürlichen Ausdehnung, die Fibrillen des Cilaskörpergerüstes in ibrer typischen, normalen Anordıung erkennen lassen.

Von den noch nicht ganz abgeschlossenen Untersuchungen sollen hier die auf Amphibien und Reptilien bezüglichen mitgeteilt werden.

Bei den meisten Tieren steht die Zonula nicht nur genetisch, sondern auch morphologisch in so innigem Verbältnis zum Glas- 
körper, dass ihre Darstellung schon zur Ergänzung des Glaskörperbildes mit herangezogen werden musste. Die Besprechung der Zonula schien auch deshalb nicht übertiüssig, weil auch bezüglich dieser die vergleichend-histologische Literatur noch eine sehr dürftige genannt werden kann, wie dies unter anderem aus der kürzlich erschienenen zusammenfassenden Darstellung des Wirbeltierauges von $\mathrm{V}$. Franz ${ }^{1}$ ) ersichtlich ist.

Bezüglich der Art der Darstellung habe ich mich an das Beispiel von Retzius ${ }^{2}$ ) gehalten und mir besonders folgenden Satz dieses Forschers zur Maxime gemacht: „Um. sie (die Beschreibung) aber so kurz wie möglich zu machen, werde ich mich vor allem an die Abbildungen halten, die besser als jede $\mathrm{Be}-$ schreibung geeignet sind, die Bauverhältnisse $z u$ demonstrieren". Der Text soll zur Erklarung der Abbildungen dienen und nicht umgekehrt. Nur jene Punkte sollen etwas ausführlicher erörtert werden, die an den Abbildungen nicht sichtbar sind.

Der Kürze zulieb habe ich auch von einer Darstellung der Geschichte unserer Kenntnisse vom Bau des Glaskörpers Abstand genommen. Es genüge ein Hinweis auf die ausführlichen historischen Darstellungen von G. Retzius und H. Virchow. ${ }^{3}$ ) - Über den speziellen Gegenstand vorliegender Mitteilung, nămlich über die Histotopographie der Glaskörperfibrillen bei Amphibien und Reptilien, liegt ohnehin bisher fast gar keine Literatur vor; die kurzen gelegentlichen Ïusserungen von Retzius und Tretjak off über das Froschauge sind das einzige, was ich in der Literatur finden konnte.

Bevor ich auf die Darstellung meiner Befunde eingehe, erfülle ich eine angenehme Pflicht, indem ich meinem verehrten Lehrer, Herrn Prof. Dr. M. v. Lenhossék, für das andauernde Interesse, das er diesen Untersuchungen von Anfang an entgegengebracht hat, meinen verbindlichsten Dank sage.

1) V. Franz: Sehorgan, in Oppel, Lehrbuch der vergleichenden Anatomie der Wirbeltiere, 1913.

$\left.{ }^{2}\right)$ G. Retzius: Über den Bau des Glaskörpers und der Zonula Zinnii in dem Auge des Menschen und einiger Tiere. Biologische Lntersuchungen, N. F. 6, 1894.

3) H. Virchow: Fücher, Zapfen, Leiste, Polster, Gefüsse im Glasliörperraum von Wirbeltieren, sowie damit in Verbindung stehende Fragen. Erg. d. Anat. u. Entwicklungsgesch. 10, 1901, S. $7+2$. 
Bekanntlich besteht der Glaskörper bei allen Wirbeltieren aus zwei Bestandteilen: einem feinen fibrillären Gerüstwerk und einer Hüssigen farblosen homogenen Interfibrillarsubstanz: als unwesentliche Bestandteile kommen dann noch einzelne isoliert im Gerüstwerk liegende zelluläre Elemente hinzu. Es scheint heute nicht mehr notwendig, auf den einstmals erhobenen Einwand einzugehen, dass das fibrilläre Gerüst ein liunstprodult, das Resultat einer Gerinnung sei. Schon die typische Anordnung dieses Gerüstwerkes schliesst diesen Verdacht vollkommen aus. ${ }^{1}$ )

Dagegen scheint es mir nötig, an der bisherigen Auffassung dieses Fibrillenwerkes eine Korrektur anzubringen. Im allgemeinen werden diese Fibrillen als starre, unverănderliche Gebilde, als Bestandteile eines passiven, sich an den aktiven Lebensvorgängen kaum mehr beteiligenden (Gerüstwerkes aufgefasst, als Bildungen, die einmal in eine bestimmte Form geprägt, diese nicht meh: verändern, sich nicht mehr weiter differenzieren kömmen.

Demgegenüber möchte ich zunächst auf jene patbologischen Beobachtungen hinweisen, aus denen hervorgeht, dass der Glas-

1) Zu den Skeptiliern gehört bis zu einem gewissen Grade auch iI. Salzmann, der sich nach $\mathrm{H}$. Virchow, von einer gewissen Bangigkeit beschlichen fühlt", was aus folgendem Satz seiner Abhandlung: Die Zonula ciliaris und ihr Verhältnis zur Umgebung, 1900, S. 40, hervorgeht: „In der Deutung des mikroskopischen Bildes müssen wir beim Glaskörper vielleicht vorsichtiger sein als bei anderen Geweben. Seine halbflüssige Beschaffenheit im Leben, die geringe Menge fester Substanz, die er auf dem Filter zurücklässt. lassen es begreiflich erscheinen, dass $\in$ S Skeptiker gibt, die das histologische Bild mehr oder weniger für ein Kunstprodukt erklären". Vielleicht trägt zur endyuiltigen Beseitigung dieser Skepsis folgender, von mir vorgenommener Versuch bei:

Ich gab den Glaskörper eines Kalbes auf einen Papierfilter und fing die ablaufende Glaskörperflüssigkeit in einer Papierschachtel auf, die ich dann in das von mir gewöhnlich angewandte Fixiermittel (Sublimat-FormalinAceton) gab, so aber, dass dieses auf die Glaskörperflüssigkeit bloss durch die Wand der Schachtel einwirken konnte, also bloss durch Diffusion, ähnlich wie dies auch bei der Fixierung des ganzen, uneröffneten Auges der Fall ist, wo die äusseren Augenhäute die Papierschachtel vertreten. Nun hatte sich aber nach 24 Stunden immer noch kein fibrillïrer Niederschlag gebildet, sondern es fand sich in der Schachtel eine vollkommen klare Flüssigkeit und am Boden ein körniger Niederschlag, der sich bei der mikroskopischen Untersuchung als aus zahllosen sehr feinen Körnern und aus einer Anzahl etwas gröberer Schollen bestehend ergab. Diese Beobachtung wirft auch auf die Entstehung der Varikositäten der Fibrillen einiges Licht. 
körper des Menschen auf die meisten Erkrankungen des Auges mit lebhaften Veränderungen reagiert, unter denen nicht nul Störungen in der Durchsichtigkeit, sondern auch eine vollkommene Vertlüssigung, d. b. ein Schwund der Fibrillen eine Rolle spielt. Dies weist darauf hin, dass der Glaskörper einem lebbaften Stoffwechsel unterworfen ist, der sich gewiss nicht nur auf die Interfibrillärsubstanz beschränkt, sondern auch die Fibrillen umfasst. Noch mehr aber ergeben die morphologischen Verhälnisse eine grosse Plastizitat der Fibrillen; sie zeigen uns, dass sich diese nach ihrer ersten Anlage nachträglich noch in sehr komplizierter Weise differenzieren, sich in bestimmter Weise gruppieren, an einzelnen Stellen verdichten, an anderen auflockern können usw.

So finden wir, dass die Fibrillen im allgemeinen die Tendenz haben, sich an alle Gebilde, die sich innerhalb des Glaskörpers befinden oder den Glaskörper unmittelbar von aussen umgeben, sekundär anzuheften, womit dann auch gewöhnlich eine bestimmte Gruppierung der benachbarten Fibrillen einhergeht. Solche Anheftungspunkte stellen die am Sebnervenkopf befindlichen Zapfen. Polster, das Pecten, die im Glaskörpel befindlichen Gefässe, die Linsenkapsel, vor allem aber die Grenze zwischen Pars optica und coeca retinae dar. Alles das sind aber sekundäre Verhältnisse, Resultate einer nachtraglichen Gruppierung des fibrillüren Bestandteiles des Glaskörpergewebes, aus der in keiner Weise Schlüsse auf die Genese der Glaskörperfibrillen gezogen werden dürfen. Dies besonders hervorzuheben, ist nicht übertlüssig, weil uns die Literatur verschiedentlich kritiklose Versuche dieser Art zeigt. So ist $z$. B. die sekundäre Verbindung der Glaskörpertibrillen mit der Gegend der Ora serrata mehrfach als Beweis dafür ausgelegt worden, dass diese (regend der Netzhaut für die Bildung und Neubildung des Glaskörpers von besonderer Bedeutung sei. Wenı man im Laufe vergleichender Studien sieht, an welch verschiedenen Stellen sich solche bündelartige Anbeftungen herausbilden können, erscheint uns das Unmotivierte eines solchen Schlusses im rechten Lichte. Wahrscheinlich ist der Glaskörper auch im vollentwickelten Tier einem ständigen Schwund und Hand in Hand damit einer Regeneration unterworfen, welche Neubildung aber keineswegs von einem ausserbalb des Glaskörpers befindlichen Gewebsbestandteil, sei es die Setzhaut, der Zapien, das Pecten, die Blutgefässe usw.. ihren Ausgang nimmt, sondern nur in einer selbstädigen Ver- 
mehrung und Differenzierung des Glaskörpergewebes begründet sein kann.

Auch bei dem Glaskörper ist es, wie bei der Muskelfaser, schwer, den morphologischen Begriff der "Fibrille" als einer letzten Struktureinheit festzustellen. Alle Übergänge von unmessbar feinen, an der Grenze der mikroskopischen Sichtbarkeit stehenden Fadchen zu mehreren Mikren dicken fibrillären Gebilden kommen vor und es ist sehr fraglich, ob nicht auch noch die allerfeinsten Fasern Multipla der letzten elementaren Einheit sind.

Besonders war es H. Virchow (a. a. ().), der auf die Frage hingewiesen hat, ob das Gerüstwerk des Glaskörpers ein zusammenbängendes Gitter oder nur eine Verfilzung selbstandiger Fasern sei. Retzius spricht sich mehr im letzteren Sinne aus, indem er zwischen den Fibrillen keine richtige Verschmelzung nachweisen zu können glaubte. - „Es sind bei stärkerer Vergrösserung deutlich sichtbare, feine, gekörnte Fasern, welche sich in den verschiedensten Richtungen kreuzen und hie und da zu Knotenpunkten zusammenlaufen; es ist zwar schwer zu eruieren, ob hier Verbindungen vorkommen; da solche aber beim Fötus auszuschliessen waren, so ist wobl kaum anzunebmen, dass sie sich beim Erwachsenen tinden" (a. a. O., S. S2). Hingegen sagt Virchow ${ }^{1}$ ): „Der Glaskörper' des Igelauges enthält keine Hüute, sondern nur Fasern, welche sich teilend und verbindend, ein nach allen Seiten gleichartiges, an verschiedenen Stellen verschieden dichtes Netz bilden." Auf Grund meiner Präparate kann ich mich mit Sicherheit im Sinne der letzteren Beschreibung, d. h. für das Bestehen eines wirklichen anastomotischen Netzes aussprechen. Allerdings ist dieser Charakter nicht an allen Stellen und nicht bei jedem Tier in gleicher Deutlichkeit ausgeprägt. Am deutlichsten ist derselbe bei Tieren mit verhältnismassig lockerem Glaskörpergerüst, so beim Frosch und den Urodelen. Bei den Ophidiern und Cheloniern ist derselbe besonders im Bereich der Zonula zu erkennen (siehe z. B. Fig. 3). Oft findet man, dass die Fibrillen in der Weise miteinander in Verbindung treten, dass sie sich schief aneinander legen und der Lange nach miteinander verschmelzen, wodurch dicke, oft ausserordentlich kräftige

1) H. Virchow: Demonstration von Augenpräparaten. Sitzungsber.

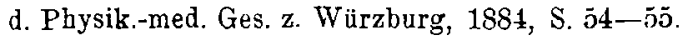


Fasern zustande kommen. ${ }^{1}$ ) Die Differenzierungen, die sich im Fibrillengerüst abspielen, das sekundüre Hervortreten besonderer Bündel und Faserströme usw. spricht von vornherein mehr für ein anastomotisches Gittel als für ein Geflecht isolierter Fäden.

Dass das Gewebe des Glaskörpers in der Form einer fibrillären Struktur erscheint, dürfte wohl seinen mechanischen Giund haben. Ein ins einzelne gehendes näheres Verständnis für diese mechanische Bestimmung haben wir aber nur bezüglich der Fasern, die sich zwischen Linse und Ciliarkörper ausspannen, d. h. bezüglich der Zonulafasern, von denen wir wissen, dass sie im Dienste der Accomodation stehen. Sie sind als das Ergebnis einer Differenzierung von Glaskörperfibrillen aufzufassen, wenn sie auch in ihrer vollen Entwicklung betrïchtlich verschieden von diesen zarten Fibrillen erscheinen und bei manchen Tieren von dem Gebiet des eigentlichen Glaskörpers durch eine membranartige Verdichtung des Glaskörpergewebes, eine ,vordere Grenzschichte", getrennt sein können. Dass aber auch das eigentliche Fibrillengewebe des Glasköıpers unter den Gesichtspunkt einer mechanischen Struktur fallt, ergibt sich aus der Tatsache, dass die Anor'dnung del Fibrillen charakteristische, konstante Verschiedenheiten bei den einzelnen Tieren aufweist, dass bei jedem Tier gewisse regelmässige Züge im Fibrillengewirr des Glaskörper's hervortreteñ. Diese typische, für die einzelnen Gattungen bezeichnende Struktur ist kaum anders zu deuten, als dass sie in ihrer Mannigfaltigkeit im Sinne einer funktionellen Anpassung an die gegebenen anatomischen und physiologischen Verhältuisse des Bulbus und der Orbita und den Bewegungsmechanismus des Auges bei dem betreffenden Tier aufzufassen ist. Sonst wire es in der Tat nicht zu verstehen, weshalb das tibrilläre Gerüst des Glaskörpers seine gleichmässige primäre Anordnung nicht auch später beibehalt.

Wir dürfen demgemäss die sich in der Anordnung der Glaskörperfibrillen aussprechenden Regelmässigkeiten im Sinne einer funktionellen Struktur, eines trajektoriellen Systems, in Beziehung stehend zu dem Innendruck des Auges und den auf

1) Natürlich sind bei der Beurteilung dieser Frage nur solche Präparate brauchbar, an welchen die gegenseitige Lage der Fibrillen nicht gestört ist. Paraffinschnitte und Zelloidinschnitte mit nachträglicher Entfernung des Zelloidins kommen daher nicht in Betracht. 
das Auge von aussen einwirkenden Kräften, deuten. Allerdings nur im allgemeinen, denn eine ins einzelne gehende Erklärung in diesem Sinne ist einstweilen noch nicht möglich. ${ }^{1}$ ) Daneben spielen offenbar auch die Verhältnisse des I'lüssigkeitskreislaufes im Innern des Auges eine gewisse Rolle, worauf aber hier einzugehen nicht der Platz ist.

Nicht nur in der Anordnung des Gerüstwerkes, auch in der Beschatfenheit der Fibrillen selbst ergeben sich charakteristische Unterschiede bei den einzelnen Tiergattungen. Ja sogar in dem Verbalten der interfibrillären Flüssigkeit gegenüber der koagulierenden Wirkung der Reagentien lassen sich gewisse, für die einzelnen T'iergattungen typische Verschiedenheiten nachweisen. Bald erscheinen die sich aus dieser Flüssigkeit bildenden Niederschlage in Form unregelmässiger, den Fibrillen regellos anhaftender Schollen, bald wieder in Form regelmissiger Tröpfchen, die den Fibrillen ein variköses Aussehen verleihen; Unterschiede, die sich angesichts der Gleichartigkeit der angewendeten Technik und angesiclits der Konstanz ihres Auftretens bei den einzelnen 'liergattungen wohl am zutreffendsten aus der verschiedenen Dichtigkeit und chemischen Zusammensetzung der Interfibrillărtlüssigkeit, nebst der verschiedenen Zahl und Starke der Fibrillen, erklären lassen. Die starksten Niederschlage findet man gewöbnlich an den Kreuzungs- oder Verüstelungsstellen der Fibrillen. Hier nehmen die Niederschläge, besonders beim Menschen, oft die Form

1) H. Virchow hat bereits die mechanische Zweckmässigkeit der Anordnung der Glaskürperfibrillen betont. "Die Gesichtspunkte" - sagt er in seinem zitierten Referate über Fächer, Zapfen usw. - „unter welchen wir die im. Glaskörperraum vorbandenen bisher bekannt gewordenen Strulituren bringen können, sind folgende drei: mechanisch zweckmässige Anordnung, Reste fötaler Bildungen, Alters- und Degenerationserscheinungen. Für bestimmte Stellen im Glaskörper, für bestimmte Modifikationen der Struktur, wird bald der eine, bald der andere der drei Gesichtspunkte lichtgebend. Bei den Resten fötaler Bildungen denken wir in erster Linie an den sogenannten Glaskörperkanal etc." Von den von Virchow hier namhaft gemachten Nomenten halte ich nur das erste, nämlich die „mechanisch zweckmässige Anordnung" für wichtig. Alters- und Degenerationserscheinungen spielen, von den höchst stehenden Säugetieren (Mensch usw.) abgesehen, keine wesentlichere Rolle und auch der Glaskörperkanal greift im allgemeinen nicht bestimmend in die Architektur des Glaskörpers ein. Siehe auch A. v. Szent-G yörgyi: Der Canalis hyaloideus im Augre des Schweines. v. Graefes Arch., Bd. 85, S. 137, 1913. 
von kleinen Tröpfchen an; es sind das offenbar die Bildungen, die schon Bowman (1848) als, nuclear granules" beschreibt. Die nucleal granules von $\mathrm{Bow}$ an sind also meines Erachtens nicht "optische Querschnitte von Fasern", wie dies von H. Virchow angenommen wurde, sondern Fallungsprodukte.

Die Niederschlagströpfchen und -schollen nehmen bei allen von mir angewandten Yethoden dieselbe Färbung wie die Fibrillen selbst an, so dass sie objektiv betrachtet als Verdicliungen der Fibrillen erscheinen. In dieser Weise sind sie auch tatsächlich von Retzi us ausgelegt worden, nach dessen Meinung die körnigen Bildungen an den Fäden nicht ats Niederschlage aus der Interfibrillarrtlüssigkeit aufzufassen sind, in welchem Falle sich solche Irörner auch zwischen den Fibrillen, unabhängig von ihuen, finden müssten, sondern als Varikositaten der Fibrillen selbst, die sich infolge der Wirkung der Reagentien direkt aus der Substanz der Fibrillen heraus gebildet haben. Mir scheint, ebenso wie H. Virchow, die Beweisführung von Retzius nicht zwingend. Man kann sich recht gut vorstellen, dass sich bei Gegenwart eines innerhalb einer Flüssigkeit ausgespannten Gitterwerkes die Niederschläge aus der Flüssigkeit aus physikalischen Gründen ausschliesslich im Anschluss an die Faden und Stabe des Gitters bilden. Mir scheint es nicht fraglich, dass es sich hier um Koagulationsbildungen des Humor vitreus handelt, der, wie es aus den oben beschriebenen Versuchen hervorgeht, einen ziemlich reichlichen Niederschlag gibt. Wären die an den Fasern sitzenden Klümpchen nichts als Varikositäten, so könnten wir fragen, wo denn der vom Humor vitreus gegebene Niederschlag ist? Doch kommt dieser Frage meiner Ansicht nach überbaupt keine grössere Bedeutung zu, wohl aber der anderen damit zusammenhängenden Frage, wie die Fibrillen tatsächlich beschaffen sind: glatt oder mit Verdickungen versehen. Nach meiner Ansicht trifft ersteres zu. Hierfür spricht, dass man manchmal Präparate erhält, an denen die Fibrillen stellenweise wirklich ganz glatt, ohne Varikosititen und Rauhigkeiten der Obertüche erscheinen, und nichts liegt näber, als anzunehmen, dass gerade dieses Bild das von allen Kunstpiodukten unbeeinflusste Verhalten wiedergibt.

Bezüglich der Frage nach der histogenetischen Bedeutung und Herkunft der Glaskörperfibrillen möchte ich in vorliegender Arbeit keine Stellung nehmen, da meine Lntersuchungen aus- 
schliesslich an völlig entwickeltem Material angestellt sind und es meiner Ansicht nach absolut verfehlt ist, aus dem Bau des fertigen Glaskörper's einen Rückschluss auf seine Entwicklung zu ziehen.

\section{Salamandra.}

Von geschwänten Amphibien wurde Salamandra maculos a untersucht. Ich benutze die Gelegenheit, um hervorzuheben, dass als Grundlage der Beschreibung nur tadellose Schnitte benutzt wurden, an denen der Glaskörper keine Schrumpfung oder sonstige Veränderungen erkennen lässt.

Das Auge des Salamanders ('laf. XIV) kann als annahernd liugelförmig bezeichnet werden. Die Hornhaut ist breit und nimmt den grössten Teil der vorderen Fläche des Auges in Anspruch, ist aber nicht sebr hervorspringend, so dass das Auge vorn nur in geringem Maße von der Kugelform abweicht. Die vordere Kammer ist breit, aber nicht besonders tief. Die Iris ist lang und dünn, in ihrer Pupillarzone verdickt, durch und durch mit Pigment beladen, so dass sie am Durchschnitt als einheitlich schwarzer Streifen erscheint. Die Linse ist gross, elliptisch, von vorn nach hinten etwas zusammengedrückt, linten ein wenig gewölbter als voln. Der Sehnerv betritt das Auge unweit vom hinteren Pol, und zwar nicht wie bei den Säugetieren nasal, sondern temporal von diesem.

Die Zonula hebt sich ziemlich scharf vom Glaskörper ab, weniger durch das deutliche Hervortreten einer besonderen Grenzschichte als vielmebr durch ibre strukturelle Versebiedenheit und den Wangel eines allmählichen C̈berganges zwischen den beiderseitigen Strukturen.

Von einer vorderen Grenzschichte des Glaskörpers kann im simne einer ausgesprochenen, gegen die Umgebung abgegrenzten Membran, wie etwa bei Siugetieren, nicbt die Rede sein, es liegt nur eine gewisse Verdichtung des Glaskörpergewebes nach seiner vorderen Grenze hin vor, die aber nach hinten zu allmählich in das gewöhnliche Glaskörpergewebe übergeht. Die Verdichtung beruht sowohl auf einer etwas gedrangteren Lagerung der Fibrillen, wie auch auf einer mässigen Konsolidierung der dazwischen gelegenen Interfibrilläsubstanz; letzterem Moment kommt meiner Ansicht nach bei allen Tieren eine nicht unbedeutende Rolle in der Bildung dieser vorderen Grenzlage zu. 
Die beschriebene Grenzschichte ist noch am ausgesprochensten im Mittelgebiet zwischen Linse und Netzhaut. Sowohl nach der ersteren, wie nach der letzteren hin hellt sie sich etwas auf. Die Linse scheinen die fibrillaren Elemente gar nicht $z$ u erreichen, indem sie sich schon früher verlieren. Deutlicher sind die Beziehungen zur Netzhaut, an die man ab und $z u$ die oft in feine $̈$ ste aufgelösten Fibrillen direkt berantreten sieht, und zwar gerade al der Grenze zwischen Pars optica und coeca, oft sogar schon etwas auf dell Bereich der Pars optica gerückt.

Auf der temporalen Seite schien mir diesc Grenzbildung um ein geringes starker entwickelt zu sein als nasal. Auf beiden Seiten zeigt die Schichte unmittelbaren Anschluss an die Zonula. Auch ist $\mathrm{zu}$ bemerken, dass an der Bildung der Grenzschichte ausser den von der Ora terminalis (serrata) zur Linse verlaufenden Fasern auch zirkular verlaufende Elemente beteiligt sincl.

Hiel möchte ich die Beschreibung der Zonula des Salamanderauges einschalten. Wir sehen einen ziemlich weiten Zonularaum. Das Fasersystem dieses Raumes weist ebenso wie beim Frosche gegenüber den höheren Vertebraten einen selır wesentlichen. prinzipiell wichtigen Unterschied auf. Die eigentlichen starren Zonulafasern bilden nicht den einzigen Bestandteil des Zonularaumes, sondern zwischen ihnen ist noch ein feineres, den Glaskörperfibrillen ahnliches Fasergeflecht nachzuweisen, dessen Elemente sowohl unter sich, wie mit den eigentlichen Zonulaelementen in reichlicher anastomotischer Verbindung stehen. In beistehender Fig. 1 ist eine kleine Partie eines Meridionalschnittes der Zonula

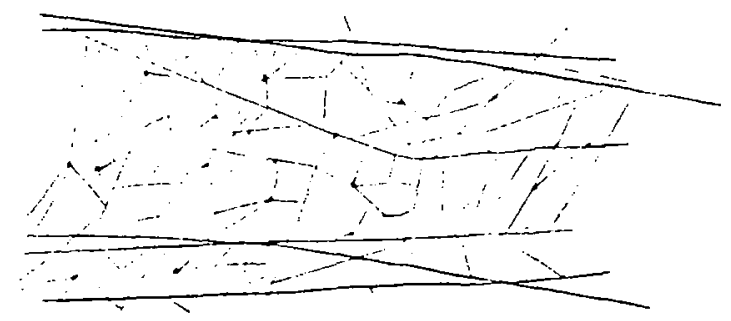

Fig. 1. Partie aus der Zonula des Salamanders Immersion.

wiedergegeben. Die schwarzen Punkte sind Querschnitte zirkulărer und schiefer Zonulafasern, auf die spater eingegangen werden soll. Man sieht, wie reichlich die Fasern durch ein dazwischen gelegenes 
zartes Netz in anastomotischer Verbindung miteinander stehen. Besonders dicht ist dieses Geflecht in der Gegend der Ora terminalis.

Die eigentlichen Zonulatasern nehmen von der ganzen Ausdehnung des Corpus ciliare ihren Ursprung. Dieser lässt sich hier ziemlich ausgesprochen in einen hinteren flachen, dem Orbiculus ciliaris entsprechenden, und einen vorderen, leicht gewölbten, die Corona ciliaris repräsentierenden 'Teil sondern. Besondere Processus ciliares sind nicht vorhanden, die ganze Bildung ist durch einen niedrigen, zusammenhangenden zirkulären Wulst vertreten, der bis zur Wurzel der Iris reicht.

An der Linse ist der Ansatz der Zonulafasern nicht symmetrisch auf den vol und hinter dem Äquator gelegenen Teil des seitlichen Linsenabschnittes verteilt, sondern es entfallen viel mehr Fasern auf das schon der vorderen Flāche angehörende Gebiet.

Die vordersten Fasern, die unmittelbar hinter der Wurzel der Iris entspringen, sind am zartesten und dichtesten; sie verteilen sich, leicht divergierend, an der seitlichen Partie der VorderHäche der Linse. Dahinter folgen etwas starkere und in weiteren Abständen stehende Fasern, von der Konvexităt des Ciliarwulstes entspringend. Sie zeigen starke Divergenz, so dass sie nicht nur am Äquator inserieren, sondern auch an der hinter dem $\ddot{q} q u a t o r$ gelegenen Linsentläcbe. Dabei zeigen sie in ihren ciliaren Wurzelteilen vielfach Kreuzungen, indem die nach hinten ziehenden Fasern oft weiter vorn entspringen als die melur nach vorn gehenden.

Die bintersten Fasern haben den glatten, Hachen Orbikularteil des Ciliarkörpers zum Ursprunge. Sie stehen in weiten $A b-$ ständen und verteilen sich unter divergierendem Verlauf am Linsenaquator und dahinter, wobei sie sich vielfach mit den vom Ciliarwulst entspringenden Fasern kreuzen.

Abweichend vom Frosche, zeigen die Zonulafasern hier nicht in der Nähe der Linse, sondern mehr in der Nähe des Ciliarepithels pinselförmige Aufsplitterungen.

An Schnitten, die mit der Linse parallel, d. h. äluatorial angefertigt sind, erkennt man deutlich, dass einerseits die Zonulafasern vielfach von der rein radiären Richtung abweichen, wobei sie sich schief durchkreuzen, anderseits aber auch ausgesprochen 
zirkuläre Fasern vorhanden sind, die, am Ciliarkörper entspringend, in die kreisförmige Richtung einlenken. Ihr endliches Schicksal konnte nicht festgestellt werden, doch scheinen sie mir nicht, wie die entsprechend verlaufenden Fasern beim Frosche, verschiedene Stellen des Corpus ciliare miteinander $\mathrm{zu}$ verbinden, sondern eine anderweitige Endigung zu haben. An den Meridionalschnitten werden natürlich die an erster Stelle erwähnten schiefen Fasern in Form kurzer Faserfragmente, die zirkulär verlaufenden als punktförmige Querschnitte erscheinen.

Gehen wir zum eigentlichen Glaskörper über, so ist hier als auffallendste Erscheinung an erster Stelle ein stärkeres Faserbündel $\mathrm{zu}$ elwăhnen, das von der hier flachen "Papilla“ nervi optici ausgehend, mit divergierenden Fasern nach der HinterHäche der Linse zieht. Dieser "Tractus centralis corporis vitrei“ ist eine weitverbreitete Erscheinung im Auge samtlicher Amphibien, Schlangen und wahrscheinlich auch bei allen Sauriern. ${ }^{1}$ ) Überall bildet dieser Tractus sozusagen den Mittelpunkt der ganzen Architektur des Glaskörpers.

Bei Salamandra nimmt dieser Tractus mit seinem Lrsprung die ganze Breite der wie gesagt hier Hachen Papille in Anspruch. Wir haben zuerst ein aus parallelen, ziemlich starken und dicht angeordneten Fasern bestehendes Bündel. Weiter nach vorn sehen wir aber, dass die Elemente des Bündels allmăhlich auseinanderweichen, und zwar mit nach aussen konkarer Divergenz. Selbst die zentralsten Fasern zeigen die Tendenz des Auseinanderweichens, bei vielfach gewundenem, etwas unregelmässigem Verlauf und mehrfachen Teilungen; auch sie erreichen die Linse nicht gerade entsprechend dern vorderen Ende der Achse des Tractus centralis, sondern in dessen Nachbarschaft. Bezüglich der seitlich gelegenen Fasern ergibt sich eine Differenz zwischen nasaler und temporaler Seite. Nasal ist die Ausbiegung der Randfasern eine gleichmässige: die Fasern erreichen noch die Linse, um an deren Kapsel zu endigen; temporal scheint die Biegung der Fasern von vornherein etwas stärher zu sein; deshalb und da das ganze Bündel infolge der temporalen Lagerung der Papille etwas temporalwärts verschoben ist, erreichen die Fasern zum

i) Das Auge der Krohodilier stand mir bisher noch nicht zur Verfügung, hierüber kann ich mich daher nicht äussern. Bei Cheloniern fehlt der Tractus centralis. 
grössten Teil nicht mehr die Linse, sondern verlieren sich, indem sie in den äusseren Glaskörper hinausbiegen, schon in ziemlicher Entfernung davon zwischen den übrigen Elementen des Glaskörpers.

Zwischen den Fasern des Tractus spinnt sich ein zartes Fibrillengerüst aus, ähnlich dem ausserhalb des Tractus gelegenen, nur ist es etwas lockerer gesponnen, daher die zentralen Teile des Tractus bei schwacher Vergrösserung eher als ein helles Gebiet des Glaskörpers hervortreten. Der Unterschied zwischen den zentralen und peripheren Teilen des Bündels wird auch noch dadurch scharfer, dass in der Peripherie des Tractus die interfibrilläre Substanz an Dichtigkeit zunimmt. Das feine interstitielle Gerüstwerk hängt unmittelbar mit den stärkeren 'Tractusfasern zusammen.

Wenden wir jetzt unsele Aufmerlisamkeit dem ausserhalb des Tractus gelegenen Teile des Glaskörpers zu, so ergeben sich, ahnlich wie bei den meisten von mir untersuchten Tieren, Differenzen zwischen den beiden Seiten, nasal und temporal, die eine gesonderte Beschreibung beider Seiten nötig machen.

Im allgemeinen ist das Bild nasal viel regelmässiger, wenn wir absehen von dem vorderen Winkel des Glaskörpers, d. h. dem sich nach vorn zuspitzenden Gebiet zwischen Netziaut und vorderer Glenzschichte. Hier liegt eine reichliche Durchkreuzung und Verflechtung der Fasern vor.

Velfolgen wir aber von hier aus die Faserung des Glaskörpers nach hinten, so sehen wir, dass sich sebr bald eine regelmïssige Anordnung der stärkeren Fibrillen einleitet. Alle Fasern zieben nach hinten. aber nicht parallel miteinander, sondern die mehr nach vorn gelegenen entsprechend der Verlaufsrichtung der Grenzschichte, d. h. nach hinten und etwas nach der Mitte $z u$, die mebr nach hinten befindlichen im Anschluss an die innere Fliche der Netzhaut direkt nach hinten; die dazwischen gelegenen Fasern nehmen in ihrer Verlaufsrichtung eine Hittelstellung ein. Im ganzen lässt sich also ein nach hinten gerichteter, leicht divergierender Verlauf der Fasern nachweisen. Innerhalb dieses zusammenhängenden Fasersystems tritt aber ein Teil beinahe als selbständiges Bündel hervor: es ist dies der Abschnitt der Faselung, der sich unmittelbar an die vordere Grenzschichte anschliesst: dieser Faserzug lässt sich in ziemlich gestrecktem Verlauf hinter der Grenzschichte und der Linse bis an den 
Tractus centralis verfolgen, mit dessen aussersten Fasern die Elemente dieser Fasergruppe zu verschmelzen scheinen. In dem Gebiet hinter dieser Fasergruppe kann von einem so ausgesprochenen regelmässigen Fasersystem nicht die Rede sein; mit schwacher Vergrösserung betrachtet, zeigt sich als dominierende Richtung allerdings die mit der Netzhaut halb und halb parallele Anordnung der Fasern, wodurch eine unverkennbare Regelmässigkeit des ganzen Bildes bedingt wird, bei Anwendung mittelstarker und starker Linsen dagegen verliert sich diese Anordnung, an den einzelnen Fasern lăsst sich der geschilderte Verlauf nur mehr ab und zu konstatieren.

Die fibrillären Elemente des ausserhalb des Tractus centralis gelegenen Glaskörpergebietes sind nicht überall von gleicher Stärke. Am stărksten sind sie vorn in dem Winkel zwischen Netzhaut und vorderer Grenzschichte: hier kommen sie an Staike den kräftigen Glaskörperfibrillen des Lacertilienauges gleich; weiter nach hinten und besonders gegen die liitte $z u$ werden sie aber allmäblich feiner und auch dichter, und in der Tähe des 'Tractus centralis haben wir ein Fibrillennetz, das in bezug auf Feinheit seiner Elemente selbst das Froschauge übertrifft und vielleicht das dichteste Glaskörperfibrillenwerk im Tierreich reprassentiert. Die Fibrillen sind hier so zart, dass dieses ganze Mittelgebiet - bei schwachen Vergrösserungen - als belle Strasse im Glaskörper hervortritt. Am Tractus lenken die Fasern allmählich in die Richtung der peripherischen Tractusfasern ein und vereinigen sich mit ihnen wahrscheinlich in der Weise, dass sie sich mit ihnen direkt verbinden.

In der Nähe der Netzhaut herrscht die konzentrische Anordnung der Fasern vor; auch mit starken Vergrösserungen betrachtet, gewinnt sie nunmehr die Oberhand, besonders in den hinteren Teilen des Auges, wăhrend gegen die Ora terminalis zu das Bild nicht so regelmässig, mehr geflechtartig ist. Aber auch diese konzentrische Gruppierung ist im Sinne eines Getlechtes $z \mathrm{u}$ verstehen, da man bei genauerer Betrachtung schiefe und sogar $a b$ und zu - senkrecht auf den vorherrschenden Faserverlauf gerichtete kurze Fibrillen walırnimmt, durch die die konzentrischen Fasern miteinander und mit der Netzhaut verbunden werden.

Temporal erkennen wir ein wesentlich verschiedenes Bild des Glaskörpers. Das Fïbrillenwerk erscheint im ganzen nicht 
so dicht und nicht so regelmässig gebaut wie nasal. Obgleich auch hier im allgemeinen die Faserrichtung eine ähnliche ist wie nasal, so ist das Bild doch sehr verschieden, da die kriftigen Fasern, die den Typus der Fibrillenanordnung in erster Linie bedingen, viel lockerer angeordnet und nicht von so gestrecktem, sondern mehr welligem Verlauf erscheinen. Auch fehlt das nasal so ausgesprochene vordere Faserbündel und ebenso ist auch das teine, lockere Mittelgebiet wwischen diesem und dem der Setzhaut anliegenden konzentrischen Fasersystem in der Nübe des Tractus nicht nachzuweisen.

Als neue Erscheinung treten hier radiäre Fasern auf, die die vorherrschende, der Netzhaut parallele, konzentrische, von aussen gegen den Tractus centralis hinziehende Faserrichtung durchkreuzen. Es sind dies ziemlich kraftige, in verschiedenen Abstinnden verlaufende, von der Netzhaut zur binteren Linsenfläche und zur vorderen Grenzschichte des Glaskörpers ziehende lasern. Ein Teil davon ergibt sich bei genauerer Cntersuchung als ein Komplex feinerer Fibrillen, andere sind aber entschieden selbständige, starke, dicke Fasern von rundem Querschnitt und lomogener innerer Beschaffeuheit; letztere Fasern machen die Iehrheit aus. Ein T'eil von ibnen hängt nur stellenweise mit den benachbarten Fibrillen zusammen; ein grosser Teil aber zeigt ziemlich reichliche Verbindungen mit den umgebenden Fasern, die sie sozusagen strangartig mit sich ziehen. Ob die Anordnung auch dem lebenden Tiere eigentümlich ist, oder nur nach dem Tode entsteht, konnte nicht festgestellt werden. Nicht alle sind gestreckt; einige zeigen wellige Krümmungen und zackige Lnickungen, doch liegt der Verdacht nahe, dass diese Lnregelmässigkeiten postmortale Erscheinungen oder Kunstprodukte sind. Die Fasern lassen oft spitzwinklige, gabeltörmige Teilungen in zwei oder drei Fasern erkennen, sie erreichen weder die Fetzhaut, noch die Linse unveründert. Schon in einiger Entfernung vor der Netzhaut erfolgt eine Aufsplitterung der Faserm, entweder in regelmüssig kegelförmiger Gestalt oder ganz unregelmüssig; erst die zarten Teilungsäste erreichen die Membrana limitans der Setzhaut. Sach vorne erfolgt die Auflösung der Fasern nicht erst unmittelbar an der Linse oder der Grenzschichte, sondern vielfach schon etwas früher. Die Auflösung der Fasern ist hier eine pinselförmige oder eine unregelmüssige. Die einzelnen Zweige 
des Pinsels sind nicht so zart, wie die Teilungsåste der Fasern an ihrer hinteren Aufsplitterung; ihr grösserer Teil verliert sich im umgebenden Glaskörper. Nur die vordersten Faserpinsel finden - auch nur zum Teile - ibre Anheftung an der Linsenkapsel oder an der Grenzschichte.

In der Fig. 1, Taf. XIV, treten diese nur temporal vorhandenen charakteristischen radiaren Fasern in ihrer typischen Eigenart hervor; leider bat der Schnitt die Richtung ihres Verlaufes nicht ganz getroffen, so dass sie nur in Bruchstücken vorliegen.

Als Grenze zwischen Netzhaut und Glaskörper erscheint einzig und allein die Membrana limitans interna retinae, die an

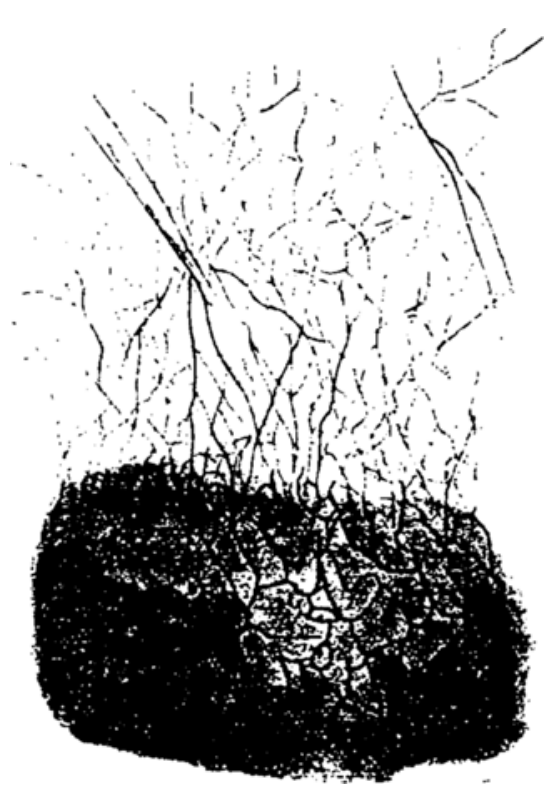

Fig. 2. Aus dem Auge von Tropidonotus natrix. Immersionsrergrösserang. Das von den Füssen der $\mathrm{YI}$ üll er schen Stützzellen gebildete Mosaik auf der inneren Fläche der Netzhaut, mit anhaftenden Glaskörperfibrillen. den Silberpraparaten stellenweise - wo zufällig eine Flachenbetrachtung derselben. vorliegt - selir deutlicb das von $G$. Retzius beschriebene. aus den Füssen der Müllerschen Stützzellen gebildete Mosaik erkennen lasst. Sonst ist bestimmt keine Grenzschichte zwischen Netzhaut. und Glaskörper vorhanden; die Fibrillen dieses letzteren setzen sich unmittelbar an der Limitans retinae an. (Eim solcher Schnitt ist von Tropidonotus natrix in der bejstehenden Textfig. 2 dargestellt.) Ich schliesse mich in. dieser Beziehung $O$. Schulze. v. Lenhossék und von den neueren Autoren Mawas und Magitot ${ }^{1}$ an. Wieso die Vorstellung einer Membrani byaloidea entstelen kounte, wäre unverständlich, wenn wir nicht wüssten, dass bei der Ablösung. der Augenhăute vom Glaskürper die Vembrana limitans interna

1) J. Mawas et A. Magitot: Étude sur le déreloppement du corps vitré et de la zonule chez l'homme. Archives d'anat. microscopique, 14, S. 41 
der Netzhaut sebr oft von der Netzhaut ableisst und dem Glaskörper anliaftet, wodurch sie eine besondere Membrana hyaloidea vortüuschen kann. Hierin liegt die Erklärung eines so lange Zeit hindurch in der Literatur festgehaltenen Irrtums.

\section{Frosch.}

Cntersucht wurde das Auge von Rana esculenta (Fig. 2, 'laf. XV) und zwar an zahlreichen Exemplaren. Das Auge des Frosches stellt ein fast kugelförmiges, nur etwas in der Richtung von oben nach unten und etwas stärker ron vorn nach hinten, $d . b$. in der Richtung seiner Achse abgeplattetes Gebilde dar. Fast die ganze vordere Fläche des Auges wird von der umfangreichen, aber in ilırer Krümmung nur wenig von der des ganzen Auges abweichenden Hornhaut gebildet. Letztere zeigt übrigens nicht wie bei Salamandra eine gleichmässige Krümmung, sondern spitzt sich ein wenig nach ihrem vorderen Pol zu. Die Linse ist gross, elliptisch, hinten stärker gekrümmt als vorn und reicht mit ihrel hinteren Fläche etwas über die Äquatorialebene des Auges hinaus.

Bevor ich auf den eigentlichen Glaskörper eingehe, möchte icb die Zonula des Froschauges betrachten. Der diese in sich schliessende Zonularaum ist ziemlich ausgedebnt, von der Form eines niedrigen Dreieckes, mit breiter, durch die Linse gebildeter Basis.

Eine „vordere Grenzschichte ${ }^{“}$ des Glaskörpers als Grenzlage zwischen diesem und der Zonula ist nur andeutungsweise vorhanden, als eine geringe Verdichtung der vordersten Glaskörperfibrillen. Tretjak off ${ }^{1}$ ) bezweifelt das Vorhandensein einel solchen Grenzschichte beim Frosch. Ich habe sie immer nachweisen können, allerdings manchmal nur in geringen Spuren. Sic zieht in gestrecktem Lauf von einer etwas vor der Ora terminalis retinae und dem vor diesem verlaufenden Ringgefâss gelegenen Stelle des Corpus ciliare zur hinteren Linsentläche. In der Nähe ibres ciliaren Ursprunges bat man Mühe, überhaupt etwas von ihr zu sehen, erst gegen die Linse hin tritt sie etwas selbstindiger hervor. Sie besteht nicht nur aus radiaren, sondern auch aus mit dem Linsenăquator parallelen, d. b. zirkulär verlaufenden Fasern. Einige starke radiare Fasern, die teilweise schon dem

1) Tretjakoff: Die vordere Augenhälfte des Frosches. Zeitschr. f. wiss. Zool., 80, 1906.

Archiv f. mikr. Anat. Bd. S5. Abt. I. 
später zu beschreibenden $R$ etzius schen Fasersystem angebören, nehmen ihren Ursprung von dem Ringgefäss.

Bei der Beschreibung der Zonula müssen wir auch hier, wie bei Salamandra, zwei Bestandteile: die eigentlichen Zonulafasern und das $z$ wischen ihnen gelegene interstitielle Fibrillennetz, auseinanderhalten.

Die eigentlichen Zonulafasern sind straffe, geradlinig verlaufende, ziemlich starke Fasern, die in ziemlich regelmässiger Anordnung vom Ciliarkörper entspringen und ohne Ǩreuzungen oder Verflechtungen făcherförmig divergierend nach der Linse ziehen, um sich an ihrer Kapsel entsprechend dem Äquator und dem vor und hinter diesem gelegenen Gebiet anzusetzen. Sie ziehen in ziemlich weiten Abständen voneinander, so dass das Bild ziemlich durchsichtig und übersichtlich ist. Gegen ihr lentiliulă'es Ende zu biegen sich die seitlichen Fasern regelmässig etwas nach vorn resp. nach binten um, wie ich es in Übereinstimmung mit Retzius finde (a. a. O., S. 84). Es ist aber fraglich, ob dies nicht als ein Kunstprodukt $\mathrm{zu}$ betrachten ist. Auch unterliegt hier eine jede Faser einer pinselförmigen Auflösung in feinere Äste. An der hinteren Grenze des Zonularaumes finden wir einen unmittelbaren Anschluss der hintersten Zonulafasern an die Grenzschichte (A. Angelucci) ${ }^{1}$ ) und in der Nahe der Netzhaut, wo eine solche Grenzschichte kaum ausgesprochen ist, an den Glaskörper und besonders an die später zu beschreibenden kräftigen Glaskörperfibrillen des "Ret $z$ i u s schen Fasersystems".

Nach vorn reichen die Zonulafasern nicht bis zur Iris, sondern lassen einen schmalen, sich gegen die Linse erweiternden Raum frei: die hintere Augenkammer.

Von besonderem Interesse ist der zweite Bestandteil des Zonularaumes: jenes feine Fibrillennetz, das sich zwischen den Zonulafasern ausspannt. Schon Retzius tut dieses Bestandteiles Erwähnung, scheint ihn aber nicht ganz richtig aufgefasst zu haben, indem er angibt, dass sich der Glaskörper mit seinen Fibrillen auch zwischen die Zonulafasern hineinerstreckt.

Es handelt sich um ein sehr zartes Fibrillengeflecht, das sich in der Tat nicht wesentlich von dem Fibrillenwerk des Glaskörpers unterscheidet, höchstens dadurch, dass es noch etwas

1) A. Angelucci: Histologische Iintersuchungen. über das retinale Pigmentepithel der Wirbeltiere. Arch. f. Anat. u. Physiol,, Phys. Abt., 1878. 
zarter und lockerer ist als dieses. Die Fibrillen hängen netzförmig unter sich zusammen und zeigen auch mit den eigentlichen Zonulafasern reichliche anastomische Verbindungen. Das Netzwerk ist im ganzen Umfange des Zonularaumes nachzuweisen; nicht nur in dem von den Zonulafasern in Anspruch genommenen T'eil desselben, sondern auch im Bereich der sogenannten "hinteren Kammer". Allerdings gelingt ihr Nachweis hier nur an einzelluen Prăparaten, da das zarte Netz offenbar durch Einwirkung der technischen Verfahren sehr leicht einer Zerstörung anheimfällt, womit dann scheinbar ein ganz leerer Raum an der betreffenden Stelle zustande kommt.

Das Interesse, das sich an die Gegenwart dieses interstitiellen Netzes knüpft, besteht darin, dass wir hier ein Stadium der Entwicklung der Zonula dauernd festgehalten sehen, das bei höheren Vertebraten nur als vorübergehende Erscheinung auftritt. Es wird sich noch Gelegenheit bieten, auf dieses interessante Verhalten einzugehen.

Ausser den radiaren Zonulafasern lassen sich auch zirkulär verlaufende Elemente nachweisen, die verschiedene Punkte des Ciliarkörpers miteinander verbinden. Tretjak off hat als erster dieses „interciliare" Fasersystem beschrieben.

Die Anordnung der Glaskörperfibrillen weist beim Frosek ausserordentlich charakteristische Verhăltnisse auf, von denen man schon in einer Abbildung von Retzius aus dem Jahre 1894 eine Andeutung findet (a. a. O., I'ig. 10, Taf. 32). Der ganze Glaskörper scheint gleichsam aus drei Abschnitten zu bestehen: einem zentralen dichteren Teil, dem Tractus centralis, einem diesen ringförmig umgebenden auffallend lockeren intermediăren Abschnitt und einer wieder etwas dichteren peripherischen, der Netzhaut năher gelegenen Abteilung. Ein Meridionalschnitt des fast kugelförmigen Auges bringt diese drei Teile übersichtlich zur Anschauung.

Vordere Kammer und Linse nehmen auf dem Durchschnitt ein sehr grosses Gebiet ein, so dass dem Glaskörper im Verhältnis zum Gesamtdurchschnitt ein verbaltnismässig geringer Raum zur Verfügung steht.

Zunächst fällt im Glaskörper der starke Tractus centralis auf, der aus einer Anzahl kraftiger, nach yorn divergierender Fasern und Faserbündel besteht, die teils an der breiten, leicht ausgehöhiten Sehnervenpapille, teils auch von deren unmittelbarer 
Umgebung entspringen. Das Bündel ist stirker entwickelt als bei Salamandra.

Sach vorn wird das Bündel beträchtlich lockerer, besonder's in seiner hinter dem Linsenpol gelegenen axialen Abteilung. Der grösste Teil der divergierenden Fasern scheint sich an der Linsenkapsel anzusetzen, die seitlichen Fasern erreichen aber die Linse nicht mebr, sondern laufen, tangential an der Linse vorbeiziehend, im Glaskörper aus.

Zwischen den stäkeren Fasern des Tractus tindet sich ein sehr zartes, lockeres Fibrillenwerk, das mit den Fasern des Tractus unmittelbar zusammenhängt.

Ausserbalb des Tractus finden wir, aut dem Meridionalschnitt, ein besonders lockeres, den Tractus ringförmig umgebendes Gebiet, gewöhnlich in Form von zwei ovalen Feldern erscheinend, das durch seine helle Beschaffenbeit ziemlich auffallend aus dem Durchschnitt hervortritt. Selten nur kreuzen einige stärkere. von der Umgebung der Papille entspringende Fasern, gleichsam aberrierende seitliche Flemente des Tractus centralis, dieses Gebiet, das nach vorn durch die seitwarts ausbiegenden Fasern des Tractus centralis begrenzt wird.

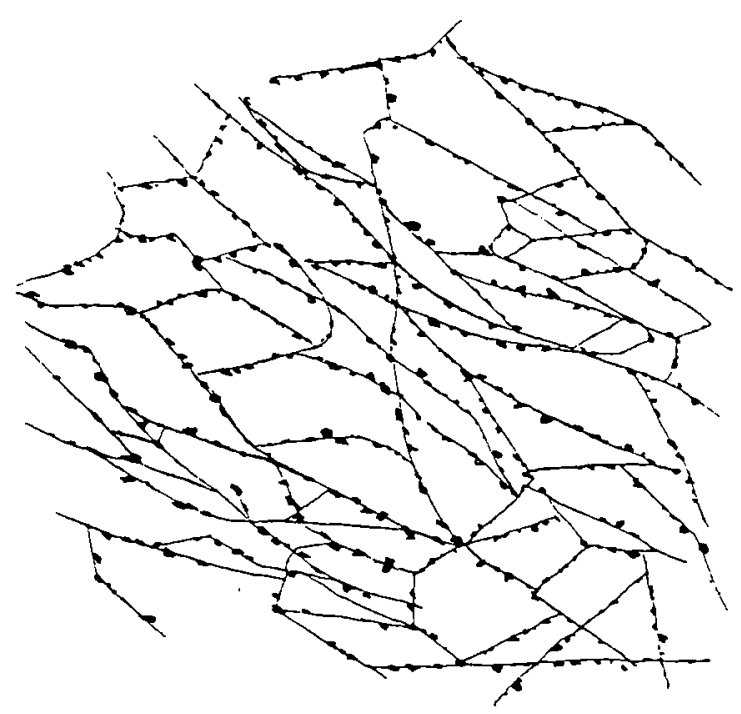

Fig. 3. Aus dem periphẹrischen Teil des Glaskörpers des Frosches. Immersion. Fibrillenwerk des Glaskörpers mit Varikositäten (Niederschläge aus der Interfibrillärsubstanz). 
Der peripherste Teil des Glaskörpers baut sich aus einem mässig dichten, fein gesponnenen Fibrillennetz auf (Textfig. 3), dessen Maschenwerk keine Orientierung erkennen lässt; selbst dicht an der Netzhaut vermissen wir die sonst so häufige lionzentrische Anordnung der Fibrillen.

Auf der Unterlage dieses feinen peripherischen Geflechtes hebt sich aber sehr auffallend eine aus gröberen Elementen bestehende Fasergruppe hervor, das Retzius sche Fasersystem, zuerst von diesem Forscher erwähnt und abgebildet. Schon bei Salamandra sahen wir etwas $̈$ Hhnliches, doch ist beim Frosch dieses Bündel viel ausgesprochener und erscheint überall, temporal wie nasal, oben wie unten, gleichmässig entwickelt. Retzius belegte es mit keinem besonderen Namen, während 'Tretjak off die betreffenden Fasern "retrozonuläre Fasern" nennt. Ich balte diesen Namen für nicht genug charakteristisch.

Betrachten wir zuerst die Bilder, die man mit schwacher Vergrösserung von dem Bündel erbïlt. Wir sehen eine Anzabl auffallend kräftiger, selbst die Fasem des Tractus centralis an stilirke übertreffender Fasern von der Gegend der Ora terminalis und zum Teile von der hinteren Oberflache des Corpus ciliare ausgehen und divergierend nach hinten ziehen. Tretjakoff beschreibt dies folgendermassen: "Diese sozusagen retrozonulüren lasern habe ich beim Frosch und der Kröte gesehen. Sie entstehen hauptsächlich auf der, hinteren Oberfläche der mittleren Ciliarfalten und verlaufen divergierend nach allen Richtungen."

Ein Teil schlägt die Richtung des rorhin beschriebenen lockeren Vittelgebietes ein. hört aber schon an dessen vorderer Grenze auf. Die meisten gehen peripherisch daron in starrem, ziemlich geradlinigem Verlauf an die seitlichen Teile der Vetzhaut hin, ohne aber die Yetzhaut selbst zu erreichen. Hie und da kann man an ihnen auch Knickungen wahrnehmen. Sie sind von verschiedener Stärke und auch ihre Abstände voneinander sind rerschieden. Der korkzieherartige Verlauf, den an manchen Prilparaten einzelne von ihnen erkennen lassen, stellt wohl ein liunstprodukt dar.

Vit stärkeren Linsen untersucht, erscheinen die meisten Fasern als selbständige, einheitliche Bildungen, andere aber die allerdicksten - manchmal als dichte Bündel feinerer Fasern, ein Lmstand, der auf ihre Entstehung ein Licht werfen könnte. 
Ibr Verbältnis zu dem zarten fibrillăren Grundnetz ist verschieden : einzelne scheinen von diesem unabhängig, mehr oder weniger isoliert zu verlaufen, andere stehen mit den benachbarten Fibrillen in innigster Verbindung. Die zarten Fibrillen heften sich oft schief, federstrahlenartig an die Faser an, was schon Retzius hervorhebt und mit dem Ausdruck kennzeichnet, dass die starken Fasern die zarteren Fibrillen "strangartig mit sich ziehen". Doch kann diese Anordnung eventuell auch eine künstlich bedingte sein.

Einzelne Fasern teilen sich unterwegs in zwei bis drei Äste oder geben unter rechtem Winkel Seitenzweige ab. Wie gesagt, erreichen sie die Netzbaut in der Regel nicht, sondern lösen sicls schon früher gleichsam unmerklich in dem feinen Glaskörpernetz auf, indem sie in zartere $\mathrm{Aste}$ zerfallen, die in das Netz übergehen. Nur in seltenen Fallen scheinen einzelne der gröberen Teilungsäste die Xembrana limitans der Netzhaut zu erreichen.

Retzius sagt folgendes: „An der Hyaloidea angelangt. inserieren sie sich an ihr vermittelst dreieckiger Ansitze, und zwar bald an Stellen, wo Blutgefässe in der Yembran liegen, bald an Stellen zwischen solchen." Die von Retzius hier elwähnten „dreieckigen" Ansätze kann ich auch bestatigen, und zwar nicht nur für den Frosch, sondern auch für andere Tiere. Man findet sie hauptsüchlich bei gröberen Fasern, aber durchaus nicht konstant; dagegen fehlen sie in der Regel bei feineren Fasern. Ich möchte aber diesen dreieckigen Ansatzkegeln keine grössere Bedeutung beimessen, und glaube, dass sie überhaupt nicht der Faser selbst angehören, sondern durch dell Zug der Fasern hervorgerufene Vorsprünge des betreffenden Gebildes, an dem sich die Fasern ansetzen, sei es nun die Membrana limitans oder ein Blutgefisss, darstellen. Damit sei nicht gesagt, dass sie immer postmortale Kunstprodukte sind; eventuell können sie teilweise schon intra vitam vorhanden sein.

Der Ursprung der Elemente des geschilderten Fasersystems an der Ora terminalis ist nicht buchistäblich zu nehmen. Bis unmittelbar an die Netzhaut selbst lassen sich die Fasern an dieser scheinbaren Ursprungsstelle kaum je verfolgen, erst in einiger Entfernung von ihr tritt das Bündel in die Erscheinung. Dagegen lasst sich wenigstens für einen Teil der Fasern eine direkte Verbindung mit dem vor der Ora terminalis verlaufenden Ringgefäss nachweisen. An dem Gefass haften übrigens auch 
noch andere Fasern, solche, die gegen die Linse und gegen die vordere Verdichtungsschichte ausstrahlen. Bei den Ansützen der gröberen Fasern an der Ader lassen sich ebenfalls stellenweise kleine dreieckige Erhebungen der Gefässwand nachweisen.

Die Anordnung der Glaskörperfibrillen in der Gegend der Ora terminalis ist von Retzius in einer schönen Abbildung dargestellt worden (Fig. 11, Taf. 32). Leider konnten alle Details an der Taf. XV der vorliegenden Arbeit, wegen der schwachen Vergrösserung nicht gut zur Ansicht gebracht werden.

Der Umstand, dass dem Glaskörper yon der p. coeca retinae nur ein sehr scumaler Streifen entspricht und dass auch dieser Streifen der p. coeca retinae zum grössten Teil vom Ringgefäss bedeckt liegt, zeigt, wie wenig begründet es ist, dieser Übergangsstelle auf Grund des scheinbaren Zusammenhanges dieser Gegend mit den stärkeren Fibrillen des Glaskörpers eine besondere $\mathrm{Be}$ deutung für die Genese und Neubildung des Glaskörpers zuzuschreiben.

Von einer Membrana hyaloidea kann auch beim Frosch keine Rede sein. Man sieht die Fibrillen des zarten Glaskörpergeflechtes allenthalben direkt an der Obertlache der Netzhaut sich inserieren. Ebenso stehen sie in inniger Verbindung mit den Blutgefässen, die beim Frosch an der Oberflache der Netzhaut liegen.

\section{Schlangen.}

Bei den Schlangen kommt man mit einer einheitlichen Beschreibung nicht mehr aus. Ës gibt vielleicht keine Ordnung ler Wirbeltiere, bei der in bezug auf die Gruppierung der Glaskörperfibrillen so verschiedene Typen obwalteten wie bei ihnen. Ich vermute, dass noch manche Besonderheiten vorbanden sind, die erst bei einer umfassenden, an einem grösseren Material angestellten Untersuchung zutage treten werden. Yir stand leider nur ein geringes Yaterial zur Verfügung, aber auch dieses gestattet schon die Aufstellung von drei Typen.

1. Bei dem ersten Typus besteht weder ein Zapfen, noch ein Tractus hyaloideus;

2. bei dem zweiten haben wir schon einen Zapfen, aber noch keinen entwickelten Kanal;

3. bei dem dritten fehlt der Zapfen, doch liegt ein vollkommen entwickelter Tractus hyaloideus vor. Zapfen 
und wohlentwickelter Kanal zusammen wurden an keiner der von mir untersuchten Spezies beobachtet. Als Vertreter der ersten Gruppe liegt der nachfolgenden Beschreibung Tropidonotus natrix, als der der zweiten Coluber caspius und als der der dritten Coluber vivax zugrunde.

Das Auge von Tropidonotus natrix (Fig. 3) erscheint von, vorn nach hinten zusammengedrückt, die auffallend dicke. gleichmässig gewölbte Hornhaut umfasst beinahe die ganze vordere Fluche des Auges. Die grosse kugelige Linse wölbt sich tief in las Gebiet des Glaskörperraumes hinein. Auch hier erfolgt der Eintritt des Sehnerven asymmetrisch, und zwar auch hier temporalwärts vom hinteren Pol, wodurch die Orientielung darüber, was im Auge temporal und nasal ist, wesentlich erleichtert wird.

Die Abgrenzung des Glaskörpers gegen den Zonularaum erscheint verschieden auf beiden Seiten. Temporal sehen wir vom hinteren Abbang des Ciliarkörpers, unweit schon von der Ora terminalis, ein Faserbündel nach der binteren Linsentläche ziehen, die erste Andeutung der bei den Süugetieren so scharf ausgesprochenen „vorderen Grenzschichte des Crlaskörpers". Das Bündel weist zwar eine etwas gedrängtere Anordnung der Fasern und vielleicht auch eine etwas dichtere Beschaffenheit der Intertibrillärsubstänz als das davor gelegene Zonulagebiet und ebenso das dahinter befindliche Glaskörpergebiet auf, doch ist es weder nach vorn, noch nach hinten scharf abgegrenzt und lässt sich in keiner Weise als richtige Membran auffassen. Die Fasern des Bündels konvergieren von der ciliaren Crsprungsstelle linsenwärts; nach der Linse hin nimmt die ganze Bildung an Dichte etwas $z u$; ein Teil scheint sich bei unverandert dichter Interfibrillärsubstanz und einer geringen Auflockerung der Fasern tangential an der Linse anzuheften, ein anderer löst sich hinter der Linse im Glaskörper auf (in der Figur ist diese Schichte etwas zu scharf differenziert dargestellt).

Auf der nasalen Seite ist die Abgrenzung der beiden Gebiete - Zonula und Glaskörper - viel verschwommener, undeutlicher. Ein ähnliches Bündel, wie es temporal beschrieben wurde, ist hier nur andeutungsweise vorhanden; es verdient hier aber nicht den Siamen eines Grenzbündels, da es keine Abgrenzung bewirkt, vielmelr im Gegenteil eher den Übergang zwischen 
Zonula und Glaskörper vermittelt, indem es sich ohne jede Grenze und ohne jede Verschiedenheit seiner Elemente einerseits an die Zonula, anderseits an den Glaskörper anschliesst. Eine verdichtete Interfibrillärsubstanz lässt sich nur in der Nühe der Linse nachweisen.

An der Wurzel der Iris, ron dieser durch einen scharfen Winkel deutlich abgegrenzt, erkenut man den ziemlich stark hervolspringenden Ciliarliörper, in Folm eines einheitlichen glatten ringförmigen Wulstes, ohne besondere Processus ciliares. ${ }^{1 j}$ Die Iris zieht schief nach vorn gerichtet in gestrecktem Lauf nach der vorderen Linsenflaiche hin, um erst unweit vom pupillaren Rand, an der Stelle, wo sie sich ganz wenig verdickt, leicht nach rorne umzubiegen.

Hier mag die Beschreibung der Zonulafasern eingeschaltet werden. Wobl kein Wirbeltier ist zur Demonstration der Tatsache, dass Zonula und Glaskörper genetisch und histologisch eng zusammengehörell, geeigneter als Tropidonotus. Die Zonulafasern erscheinen bier als nur um ein geringes verdickte Glaskörperfibrillen, von letzteren hauptsachlich nur durch eine bestimmte Anordnung und durch biundelartige Gruppierung unterschieden. Ich bemerke, dass in der Tafel die Zonulaèlemente zu kräftig: ihre Anordnung zu regelmïssig; das ganze Bild der Zonula zu sehr schematisiert dargestellt ist.

Die Zonulafasern nehmen das ganze Gebiet $z$ wischen Iris, Linse und Glaskörper ein; cine zonulafreie sogenannte hintere Kammer besteht nicht. Die lasern zejgen vorn, dicht hinter der Iris, eine gedrangtere Anordnung als hinten. Ihr Lirsprung erfolgt am Corpus ciliare, mit Ausnahme seines bintersten Teiles, der, wie oben geschildert, dem Cirenzbündel zum Crsprunge dient. Das Zonulabündel zieht parallelfaserig oder nur leicht divergierend ungefähr bis zur Stelle, wo sich die Iris schief nach vorn auszubiegen beginnt, von hier ab leitet sich eine starkere Divergenz del Fasern ein. Die Anordnung der Fasern ist aber ron hier $a b$ nicht regelmassig; sondern geflechtartig zu nennen,

1) Ciliarfortsätze sind weder bei den Ophidiern, poch bei den Sauriern vorhanden. Siehe diesbezüglich des Näheren: F. Kopsch, Iris und Corpus ciliare des Reptilienauges, nebst Bemerkungen ïber andere Augenteile. Berlin 1892, und V. Franz, Selrorgan, in Oppels Lehrb. d. vergl. mikr. Anat. d. Wirbeltiere 1913 . 
indem sie sich häufig schief überkreuzen, vorn entspringende Fasern mehr nach hinten zieben und umgeliehrt. Besonders hâufig sind die Kreuzungen entsprechend dem Äquatorialgebiet der Linse. Vit schwachen Linsen betrachtet, ist die Zonula hiel einem der Länge nach stark ausgezogenen Netze ahnlich. Teilungen der einzelnen Fasern sind sehr oft zu sehen, daneben geben die Fasern vielfach zarte Nebenaste $a b$, durch die sie sich mit den benachbarten Elementen netzförmig verbinden. Diese feinen Nebenaste der Fasern entsprechen wahrscheinlich dem zarten intermediuren Fibrillengeflecht der Zonula des Frosches und des Salamanders. Im allgemeinen ist der netzförmige Zusammenhang der Fasern in der Zonula von Tropidonotus ziemlich stark ausgesprochen.

Ich möchte auf diese netzförmige Anordnung der Zonulit als auf eine prinzipiell wichtige Tatsache besonderen Nachdruck legen. Wir sehen darin, ebenso wie im beschriebenen intermediären Fibrillengeflechte der Zonula des Frosch- und Salamanderauges, eine histogenetisch frühere Entwicklungsstufe der Zonula festgehalten. Aus den Untersuchungen von Retzius, Lenhossék u. a. wissen wir, dass sich die Zonula aus einem typischen netzförmigen Glaskörpergewebe herausbildet unter Hervortreten stärkerer cilio-lentikulärer Züge und unter allmăhlichem Schwund der Verbindungsfibrillen $z$ wischen den stärkeren Zügen. Hier ist nun das primitive netzförmige Stadium, wenn auch nicht in seiner vollen Ausprägung, aber doch in einzelnen Resten erhalten. Das phylogenetisch tiefer stehende Verbalten deckt sich also hier mit einem thistogenetisch primitiveren Bild, ein Verhalten, dem wir beim Studium der Zonula und des Glaskörpers seh! oft begegnell.

Der Ansatz der Zonulafasern an der Linse umfasst den Aquator sowie das davor und dahinter befindliche (iebiet. In der Regel zertallen die Fasern, bevor sie an der Linse ihre Anheftungsstelle erreichen, pinselförmig noch in feinere Zweige.

Wie gesagt, erscheint das Zonulabündel vorn am dichtesten und stellt sich nach binten beträchtlich lockerer dar. Besonders locker erscheint die Anordnung der Fasern vor der sogenannten Grenzschichte. Unmittelbar vor dieser liegt eine Faserpartie, die schon ganz dieselbe Struktur aufweist wie der Glaskörper.

Gehen wir zur Beschreibung des Glaskörpers über, so ist hervorzuheben, dass auch hier die Sehnervenpapille den Zentral- 
punkt für die Anordnung der im Glaskörper hervortretenden besonderen Fibrillenbündel darstellt. Die Vertiefung an der Eintrittsstelle des Sehnerven wird durch einen ziemlich starken Gliawulst ausgefüllt, von H. Virchow treffend als "Polster" bezeichnet. In diesem Polster erfolgt die Verästelung der durch den Sehnerven in das Auge tretenden Arteria centralis retinae, und zwar in vier divergierende $\ddot{A}$ ste, die sich sofort an die innere Fläche der Netzhaut anlegen, um unter reichlicher Verastelung nach der Gegend der Ora terminalis zu ziehen, immer in engem Kontakt mit der Netzhaut. Von den vier Ästen ist einer stärker als die anderen, nämlich der temporale.

Von der leicht ausgehöhlten Fläche des Polsters sehen wir ein Bündel stärkerer Glaskörperfasern entspringen und divergierend fächerförmig nach allen Richtungen, vorzugsweise aber nach vorne ziehen. Die Anordnung der Fasern ist etwas dichter in den axialen Teilen des Bündels, nach der Seite bin wird sie allmählich lockerer. Die axial gelegenen Fasern lassen sich zum grössten Teil vorn bis zur Linse verfolgen; sie setzen sich an der hinteren Oberflache der Linsenkapsel an. Die seitlichen Fasern strablen in den peripherer gelegenen Glaskörper aus, wo sie eine Strecke weit zu verfolgen sind. Dieses Fasersystem entspricht dem beim Frosche beschriebenen Papillenbündel (Tractus centralis), nur sind die Fasern schwächer als die entsprechenden Elemente im Auge des Frosches. Hier verdient diese Bildung den Namen „Bündel“ nicht, da sie neben ihrer lockeren Beschaffenheit mit dem Glaskörper verfilzt ist. Zwischen diesen stärkeren Fasern befindet sich ein aus zarten Fasern bestebendes Fibrillennetz, das mit den groben Fasern ebenso wie beim Frosch vielfach zusammenhängt.

Voll den Zweigen der Arteria centralis retinae üben drei keinen besonderen Eintluss auf die Anordnung der Glaskörperfibrillen aus. Sie hängen zwar mit den Fasern zusammen, aber nicht mehr; als die sonstigen Bildungen, die mit dem Glaskörper in Berührung stehen. Yur der vorhin als besonders stark charakterisierte temporale Ast der Zentralarterie bildet bald nachdem er im Bereich des Polsters an die Obertläche gelangt ist. den Ausgangspunkt eines besonders kräftigen selbståndigen Faserbündels, das im Anschluss an das beschriebene Papillenbündel ebenfalls in der Richtung der Linse zieht, und zwar zu 
einer vom hinteren Pol etwas temporalwatts gelegenen Stelle derselben. Eigentlich haben wir es hier gar nicht mit einem Bündel, sondern mehr mit einem trichterühnlichen Hohlgebilde zu tun, das wir Tractus hyaloideus nennen wollen, ohne bier zunächst auf eine Beweisführung für die Richtigkeit des Namens einzugehen.

An einem horizontalen Schnitte sehen wir, dass die Wände des Tractus ebenfalls nach vorne divergieren. Die Wandung des Tractus wird von einer etwas dichteren Interfibrillarsubstanz, von einem ungemein feinen Fibrillennetz und von stärkeren, von der Obertläche des Gefasses entspringenden Fasern gebildet, die den Fasern des Tractus centralis ähneln. Ein Teil dieser Fasern zweigt vereinzelt oder in Form sich bald auflösender lockerer Membranen in den Glaskörper ab. Im Hintergrunde des 'Auges erscheint die Wandung des 'l'ractus mit schwacher Vergrösserung betrachtet als selbständige, ziemlich starke Membran, während sie sich vorne, gegen die Linse zu, beinahe ganz auflöst, indem nur ein geringer Teil ihrer Fasern an der Capsula lentis haftet, während der grösste Teil sich im übrigen Glaskörper verliert.

Im Inneren des Tractus findet sich ein lockeres, aus zarten Fasern bestehendes Fibrillennetz, das mit den groben Fasern, die es durchziehen, ebenfalls vielfach zusammenhangt. Besonders weitmaschig und locker ist dieses Grundgewebe in den hinteren 'Teilen des Bündels, wo es den Anschein haben kann, als würden die nach vorne strebenden stärkeren Bündel in einem förmlichen Kanal des Glaskörpers verlaufen. Bei nüherem Zusehen erkennt man aber, dass von einem wirklichen Kanal auch hier nicht die Rede sẽin kann, indem das feine Cilaskörpergerüst nirgends vollkommen fehlt. Ein richtiger Kanal ist im Glaskörper überhaupt bei keinem von mir untersuchten Tier - die Säugetiere mit inbegriffen - vorhanden, sondern höchstens ein lockerer gewebter "Tractus", der allerdings gegen die dichtere Lmgebung mehr oder weniger scharf durch eine membranartige Verdichtung des

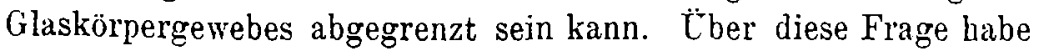
ich mich bereits eingehender in meiner schon zitierten Arbeit über den Canalis hyaloideus des Schweines ausgesprochen.

Die die Wandung des Tractus bildenden Fibrillen gehen von den seitlichen Teilen des freiliegenden Stückes des temporalen Gefässastes. ab, während der höchste Punkt der Konvexităt 
desselben schon frei innerhalb des l'ractus liegt. Die Basis des Tractus, die zum 'Teil schon ausserhalb des Bereiches der Papille liegt, ist in der Verlaufsrichtung des Gefässes verzogen, wodurch der Querschnitt des Tractus hyaloideus vor der Netzhaut zu einem elliptischen wird. Nach vorn wird aber der Querschnitt mehr und mehr zu einem kreisförmigen.

In einiger Entternung von der Papille hört das Gefäss auf, einem besonderen "Tractus" zum lirsprunge zu dienen, dagegen behalt es nach wie vor seinen engen Zusammenhang mit den Glaskörperfibrillen. Wenn wir an einer, schon in einer gewissen Entfernung von der Papille befindlichen Stelle einen Querschnitt des Gefässes und des benachbarten Glaskörpergebietes ins Auge fassen, so sehen wir ein Bild, das an die aufgehende Sonne erinnert (Textfig. 4). Die zarten Fibrillen scheinen wie divergierende Strahlen von der Gefässwandung nach allen Richtungen -

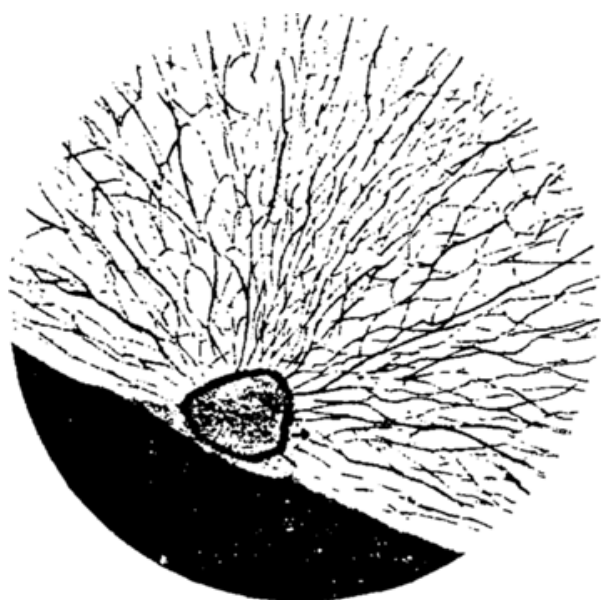

Fig. 4. Aus dem Auge von Tropidonotus natrix. Immersion. Querschnitt eines Astes der Arteria centralis retinae, strahlenförmiger Ansatz der Glaskörperfibrillen am Gefïss.

natürlich mit Ausnahme der de! Netzhaut zugekehrten - auszugehen. Die in der Richtung des Tractus hyaloideus ziehenden Fasern sind etwas dichter angeordnet. Sie gesellen sich zum Teil zu den Fasern, die die Wandung des Tractus bilden. Hinten, in der Nähe des Tractus, ist hier ein ganzes Bündel wahrzunehmen. Die Verbindung der Fibrillen mit der Gefässwand scheint eine richtige Anheftung, nicht nur ein obertlächlicher Kontakt 
zu sein; die vorher besclıriebenen kegelförmigen Verdickungen an den Ansatzstellen der Fibrillen sind auch hier vielfach nacbzuweisen.

Die beiden von der Sehnervenpapille und vom Gefäss entspringenden Bündel halte ich trotz ihres engen Anschlusses aneinander und trotz der Vermischung ihrer Fasern für besondere Bildungen, die eine besondere Beurteilung erheischen. Das Papillenbündel entspricht dem vorhin beschriebenen Tractus centralis im Auge des Frosches und des Salamanders, während wir im „Gefăssbündel" die ersten Spuren einer neuen Bildung, die bei den nächstfolgenden Reptilien in stärkerer Ausprăgung als Tractus hyaloideus erscheinen wird, erkennen.

Besondere Beachtung verdienen die Verhältnisse des Glaskörpers in der Gegend der Ora terminalis. Hier findet man zunächst dicht an dem Beginn der Pars coeca den Querschnitt eines Gefïsses - es ist dies die Ringvene des Glaskörpers, das zirkuläre Sammelgefäss der an der Innenflache der Netzhaut von der Papille peripherisch ausstrablenden Gefässe. Der Gefassquerschnitt ist aber nur auf der einen Seite, und zwar auf der temporalen, gut sichtbar, auf der anderen kaum $z u$ erkennen. Dicht vor dem Gefäss fängt dann gleich das beschriebene Grenzbündel zwischen Glaskörper und Zonula an. Innerhalb des eigentlichen Glaskörpergebietes liegt also die Pars coeca retinae nirgends frei; die kleine, dem (ilaskörpergebiet entsprechende Stelle desselben wird vom Ringgefäss bedeckt. Unter solchen Umständen kann es natürlich auch nicht zur Bildung eines Retziusschen Bündels kommen. Hier liegt es mithin klar zutage, dass die Übergangsstelle zwischen Pars optica und coeca retinae unmöglich von besonderer Bedeutung für die Genese des Glaskörpers sein kann.

Was den ausserhalb des Tractus betindlichen Teil des Glaskörpers betrifft, so ist zunachst hervorzuheben, dass das Fibrillenwerk desselben in seiner Beschaffenheit eine grosse Ïhnlichkeit mit dem der Eidechsen erkennen lasst. Wie bei diesen sind die Fibrillen verhältnismässig grob, mit wenig ausgesprochenem netzförmigen, anastomotischen Charakter. Lokale Unterschiede treten relativ wenig hervor, so dass das Übersichtsbild des Glaskörpers ein gleichmässiges, klares, einfaches Bild darbietet. Etwas starker ist das Faserwerk in der unmittelbaren Umgebung des Tractus hyaloideus, innerhalb des zu beschreibenden etwas lockeren Ge- 
bietes und ebenso vorn in dem Winkel zwischen vorderem Grenzbündel und Ora terminalis.

Wie bei den anderen Tieren, setzt sich das Fibrillenwerk des Glaskörpers auch hier aus zwei Fasergattungen zusammen: aus regelmăssig, gestreckt oder leicht bogenförmig, in melır oder weniger gleichen Abständen und oft ganz parallel verlaufenden Fibrillen und aus einem dazwischen liegenden völlig unregelmässigen, wirren, einem Wattebausch gleichenden (Salzmanns Vergleich) Faserwerk. Bei Tropidonotus ist das erstere, regelmussigere Fasersystem verhältnismässig sehr gut entwickelt und liisst sich mit Sicherheit unter dem Mikroskop von letzterem trennen, wodurch eine gewisse Regelmässigkeit des Bildes bedingt wird, doch wird die Regelmässigkeit der Anordnung gerade nur an einigen Schnitten in ihrer charakteristischen Eigenart zum Vorschein kommen können, an den Schnitten nämlich, die in die Axialebene des gewöhnlich von einem Punkt oder einer umschriebenen Stelle ausstrahlenden Fasersystems fallen, da alle anderen Schnitte die Fasersysteme in schiefen oder queren Durchschnitten zur Schau tragen und daher keinen Einblick in deren Anordnung gewähren.

Auch hier ergeben sich Unterschiede in der Anordnung der Fibrillen auf den beiden Seiten, temporal und nasal.

Temporal erkennen wir zunächst dicht hinter dem beschriebenen vorderen Grenzbündel einen Strom dichterer Fasern, der parallel mit dem genannten Grenzbündel die Richtung der Linse einschlägt, ohne letztere aber zu erreichen; schon früher löst sich das Fasersystem auf. In dem Bündel finden wir auch besonders starke Fasern, die ihren Ursprung teils von dem an der Übergangsstelle von Pars optica und coeca retinae gelegenen Ringgefäss, teils dabinter, an der Ora terminalis nehmen.

Weiter papillarwärts, immer noch im Bereich der Ora terminalis, folgt ein dichteres, aus unregelmässig verflochtenen Fasern bestehendes Gebiet. Eine bestimmte Faserrichtung lässt sich darin zunăchst nicht feststellen. Etwas weiter nach hinten prăgt sich wieder mehr eine bestimmte Direktion der Faserströmung aus. Immer noch handelt es sich um Fibrillengruppen, die von der Gegend der Ora terminalis ihren Ursprung nehmen. I)ie Richtung ist zunächst eine gegen die mittleren Teile des Tractus hyaloideus orientierte; weiter nach binten lenkt aber der 
Verlauf der Fibrillen mehr in eine tangentiale, der Netzhautobertläche parallele ein. In solchem Verlauf lasst sich ein Teil der Fasern bis in die Yihe des Tractus hyaloideus verfolgen. Ein Teil verlässt aber schon früher die der Netzhautoberfläche parallele-Verlaufsrichtung, um bogenförmig in die inneren Teile des Glaskörpers einzubiegen. Diese Fasern stehen in gleichen Abstïnden voneinander und zeigen einen ziemlich streng parallelen Verlauf. Sie kreuzen im Innern des Glaskörpers ein anderes Fasersystem, das aus Fasern besteht, die von del Gegend der Ora terminalis direkt gegen den Tractus verlaufen und ebenfalls aus Fasel'l besteht, die in parallelem Verlauf in gleichen Abständen voneinander stehen. Die sich kreuzenden Fasel'n der beiden letztgenannten Systeme umfassen miteinander kleine regelmasssige rautenförmige Zwischenräume.

Ein weiteres System von Fibrillen kommt nur an Äquatorialschnitten des Auges zur Anschauung. Es sind dies zirliulare Fasern, am besten entwickelt in der Gegend der vorderen Grenzschichte, an deren Bildung sie Anteil nehmen. Zwischen den Fasern der beschriebenen Fibrillensysteme liegt die zweite Fasergattung: die aus unregelmaissigen, wattebauschähnlichen Faserı besteht, die gar keine Orientierung erkennen lassen.

Nasal liegen die Verhälnisse im wesentlichen ebenso wie auf der temporalen Seite, immerhin aber mit einigen geringeren Unterschieden. Eine besondere Grenzschichte kommt hier, wie schon beschrieben, nicht zur Entwicklung. Die von der Gegend der Ora terminalis ausstrablenden Faserströme sind zwar auch hier vorhanden, unterscheiden sich aber durch ihre Kürze von den analogen Bündeln der temporalen Seite; schon unweit ihres Ursprunges verlieren sie sich, und so lasst der grösste Teil des Glaskörpers in dieser Augenhalfte jene für die andere Seite so charakteristische Regelmässigkeit der Anordnung der Fibrillen vermissen. Da hier das Ringgefäss sehr schwach entwickelt ist, lassen sich die Fibrillen bis zur Netzhaut, in ihrem Übergangsgebiet zwischen Pars optica und coeca, verfolgen.

Hier ist der Platz, um ein bisher noch nicht erwähntes Fibrillensystem zu beschreiben, das, weun auch temporal in Spuren vorbanden, erst nasal mit Deutlichkeit hervortritt. Es sind das radiäre Fasern, die, von der Innentläche der Netzbaut ausgehend. in ziemlich weiten, ungefähr gleichen Abständen voneinander die 
anderen Fasersysteme durchkreuzen, indem sie von der Netzhaut aus in der Richtung der Linse und der vorderen Grenzschichte ausstrablen. Die Fasern sind verhältnismassig stark. Sie verlaufen nicht immer ganz geradlinig; sowohl nach der Netzhaut wie nach der Linse hin splittern sie sich in feinere Fibrillen auf. Ich bemerke, dass dieses Fasersystem in der Zeichnung (Taf. XVI) etwas $\mathrm{zu}$ stark hervortretend und $\mathrm{zu}$ regelmässig dargestellt ist, besonders temporal, wo es, wie erwăhnt, nur in Spuren vorhanden ist. Dieses Fasersystem können wir als eine bald vergehende Bildung im Saugetierembryo wiederfinden.

Eine Besonderheit der nasalen Seite gegenüber der temporalen ist, dass hier in der Nachbarschaft des Tractus hyaloideus eine lockerer gefügte Partie im Glaskörper nacbzuweisen ist, ăhnlich derjenigen, die beim Frosch an derselben Stelle beschrieben wurde, und derjenigen, die bei den Lacertiden - wie dies beschrieben werden soll - in Erscheinung tritt.

Bei Tropidonotus lasst sich ebenso wie bei den anderen Tieren vielfach ein direkter Ansatz der Glaskörperfasern sowohl an der Yietzhaut, wie an der Linsenkapsel beobachten, wobei die Fasern in der Regel vol ihrer Anheftung in feinere Fibrillen zerfallen. Eine besondere Membrana hyaloidea besteht auch bei diesem Tier bestimmt nicht; die Insertion der Fibrillen erfolgt unmittelbar an der Membrana limitans interna der Netzhaut. Die bei Salamandra beschriebene, mit der Netzhaut parallele, ihr unmittelbar anliegende Fibrillenschichte fehlt bier.

Coluber caspius. Das Auge weicht in seiner Form und inneren Beschaffenheit nicht wesentlich von dem des Tropidonotus natrix ab. Als Novum erscheint nur an der Papilla nervi optici statt des flachen Polsters ein kleines keilförmig hervortretendes Gebilde, der von H. Virchow als "Zapfen" bezeichnete Vorsprung. An den von mir untersuchten nicht sehr alten Exemplaren von Coluber erschien das Gebilde als ein nur 0,2 bis $0.25 \mathrm{~mm}$ langes, an dem verdünnten Ende abgerundetes Gebilde.

Bezüglich der genaueren Beschreibung des Zapfens und der verwandten im Glaskörpel vorkommenden Gebilde verweise ich auf die zitierte Abhandlung von $H$. Virchow und auf die von D. Tretjak off: Das Auge vom Renntier. Intern. Nonatsschr. f. Anat. u. Physiol., 29, S. 150, 1912. Den Hauptbestandteil des Zapfens bildet ein reicher Gefässplexus, den pigmentierte Zellen Archiv 1. mikr. Anat. Bd. 8j. Abt. I. 
umhüllen und durchdringen. Der histologische Charalitel des Grundgewebes des Zapfens und seiner Zellen ist noch niclit aufgeklart; hier sind embryologische Untersuchungen nötig. Einstweilen kann man nur mit einiger Wahrscheinlichkeit annehmen, dass es sich um eine Gliawucherung handelt.

An der Basis des Zapfens treten die inneren Glaskörpergefässe aus dem Sebnerven hervor, und zwar drei bis vier ungefïhl rechtwinklig divergierende $\ddot{\text { Aste. }}$

Die Zonula unter'scheidet sich nicht von der des Tropidonotus. Die "Grenzschichte des Glaskörpers" scheint mir hier dagegen um ein geringes scharfer ausgeprägt zu sein.

Auch in der Struktur des Glaskörpers liegt eine Übereinstimmung vor, bis auf den Ursprung und die Verlaufsverhältnisse des Tractus centralis, die durch die Gegenwart des Zapfens beeintlusst werden. Während bei Tropidonotus diese Fasergruppe an der tlachen Papille entspringt, nimmt sie hier an der ganzen Ausdehnung des Zapfens ihrell Ausgang, am dichtesten aber von deren Spitze. Auch ist der ganze l'ractus centralis bedeutend stârker entwickelt als bei Tropidonotus und nimmt daher an der Architektur des Glaskörpers einen wesentlicheren Anteil, mit dem er hier noch inniger verfilzt ist. Innerhalb dieser Faserausstrahlung tritt ein starkes zentrales Bündel selbständig hervor: der Tractus hyaloideus. Er entspringt nicht an der Spitze des Zapfens, sondern von der. einen Seite desselben, seltener von dessen Basis, ja gelegentlich zum Teil sogar neben der Basis an einem Ast der Zentralarterie. Dieser Ast nimmt gegenüber den übrigen Ästen des genannten Gefüsses vermöge seiner eindringlicheren Beziehungen zum Glaskörper eine besondere Stellung: ein. Auch bei Tropidonotus begegneten wir diesem Ast; wăhrend er aber dort die anderen Äste an Starke übertraf, ist er bei Coluber gerade am schwächsten. Ich halte es nicht für unmöglich, dass die Bildung des Zapfens mit der Reduktion dieses Astes bei Coluber irgendwie zusammenuăngt; doch geben meine Prüparate, die nur vollkommen entwickeltes Naterial betreffen, hierüber keine befriedigende Aufklirung; spezielle Lntersuclungen haben hier einzusetzen.

Das vom Zapfen entspringende Fasersystem des Tractus hyaloideus bildet auch hier einen sich gegen die Linse erweiternden Zylinder, der durch die starken peripherischen Fasern 
und eine etwas verdichtete Interfibrillärsubstanz gegen die Lmgebung ziemlich scharf abgegrenzt ist. Im Innern des Tractus findet sich auch hier ein besonders lockeres Fibrillennetz, das sich schon dem Bilde eines "Canalis" hyaloideus sehr nähert.

Die sonstigen Verhåltnisse des Glaskörpers schliessen sich an die bei Tropidonotus an.

Coluber vivax (Textfig. 5). Das Auge ist bedeutend kleiner als das der beiden bisher abgehandelten Schlangen. Der besonders schmale Orbicularteil des Ciliarkörpers wird durch das Ringgefass vollkommen verdeckt. Ein "Zapfen * fehlt; besonders

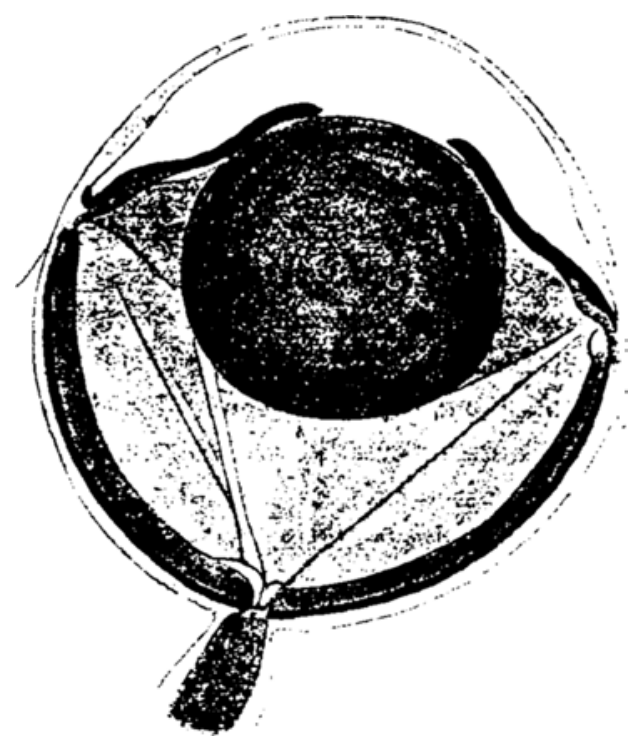

Fig. 5. Auge von Coluber vivax. Schwache Vergrösserung.

hervorzuheben ist die auffallend ștarke Entwicklung jenes Astes der A. centralis retinae, der — wie dies auch bei den bisher betrachteten Formen der Fall war - einem besonderen Faserbündel des Glaskörpers, dem Tractus hyaloideus, zum Ursprunge dient. Die Zonula zeichnet sich durch feine Beschaffenheit und dichte Anordnung ihrer Elemente aus.

Als neue Erscheinung tritt hier die Trennung des Glaskörpers in zwei Abschnitte: einen schmalen peripherischen und einen zentraleren Abschnitt auf. Die Grenze zwischen beiden ist in Form einer zarten Verdichtungsmembran des Glaskörper- 
gewebes erkennbar, die linten, im Umkreis der Papille entspringend,. unter Abgrenzung eines von ihr umfassten weiten trichterförmigen Raumes ringsum in der Năle des Ciliarkörpers ihr Ende findet. Innerhalb dieses inneren "Glaskörpergebietes fallt zunăchst ein besonderer exzentrisch gelegener Teil auf, den wir nunmehr schon als Canalis byaloideus bezeichnen können. Allerdings bandelt es sich nicht um einen wirklichen offenen Kanal, sondern nur um einen schmalen röhrenförmigen Abschnitt des Glaskörpers, der sich durch besonders zarte und lockere Beschaffenheit seines Fibrillennetzes auszeichnet und nach aussen einigermassen durch ein membranartiges Verdichtungsgewebe abgeschlossen ist. Dieses Grenzgewebe besteht hauptsäcllich aus Lăngsfasern und verdichteter Interfibrillărsubstanz. Der Kanal selbst ist ein schmaler, langer, gestreckter Gang, der sich nur hinten in der Silie der Papille etwas erweitert. Seine Endigung erfolgt nicht in der Mitte der hinteren Linsentlache, sondern beträchtlich seitlich davon, schon nahe zur Ansatzstelle der Grenzschichte. Beobachtet man genauer den Ursprung der Grenzmembran dieses Kanals an der Papille, so sieht man, dass derselbe an dem schon oben erwahnten Ast der A. centralis retinae erfolgt, und zwar an der Stelle, wo er auf die Oberflăche del Papille tritt.

In dem Abschnitt des inneren Glaskörpergebietes, der sichı zwischen dem Canalis byaloideus und der ausseren Grenzmembran des inneren Glaskörperabschnittes befindet erkennt man eine Anzahl stärkerer Längsfasern (in der Textfigur nicht dargestellt), die von der Papille entspringend, divergierend nach vorne ziehen. um sich teils in der Nähe der Linse, teils in der Gegend des Zwischenraumes zwischen Linse und Ciliarkörper zu verlieren. Allem Anschein nach entsprechen diese Fasern wie überbaupt der ganze trichterförmige innere Glaskörperabschnitt mit Abrechnung des darin befindlichen Canalis hyaloideus dem Tractus centralis der Amphibien und Scllangen.

\section{Eidechsen.}

Untersucht wurden Lacerta viridis (Fig. 4) und muralis. letztere an wenigen Exemplaren. Ein grösserer Unterschied zwischen den Augen der beiden Formen liess sich nicht feststellen, weder in der inneren und ausseren Gesamtgestaltung des 
Auges, noch im speziellen in den Verbăltnissen des Glashörpers und der Zonula.

Das Auge weist eine recht eigenartige Form auf; es ist, als ob die ganze vordere Hälfte des kugelförmigen Auges durch einen Schnitt abgetragen wäre. In dem Mittelgebiet dieser vorderen flachen Fläche erbebt sich die sich mässig hervorwölbende Hornhaut: Die im Verhältnis zu den Amphibien und auch $\mathrm{zu}$ den Schlangen eher kleine Linse weist eine elliptische, vorne flachere, hinten gewölbtere Form auf.

Auffallend ist die grosse Ausdehnung der Pars ciliaris retinae; der Ciliarkörper geht ohne scharfe Grenze in die hintere Fläche der Iris über, er selbst ist kaum in einen Orbiculus ciliaris und eine Corona ciliaris zu trennen, da Ciliarfortsätze nicht vorhanden sind und die Verdickung des Ciliarkörpers von der Ora terminalis nach der Iris hin allmählich erfolgt.

Ein mächtiger "Zapfen" tritt bier in Erscheinung, von der" ganzen Breite der leicht napförmig vertieften Papille des Sehnerven mit einer etwas verbreiterten Basis ausgehend. Das Gebilde richtet sich genau nach dem hinteren Pol der Linse hin, erreicht ibn aber nicht, sondern endigt an der Grenze des vordersten Fünftels des lenticulo-papillaren Abstandes etwas verschmalert und abgerundet. Wie schon Kessler richtig angibt, beträgt seine Dicke ein Fiertel seiner Lănge.

Die Zonula nimmt im Verhältnis zur Gesamtausdehnung des Auges ein auffallend kleines Gebiet ein, was sich daraus erklärt, dass der Ersprung der Zonulafasern ausschliesslich von einer eng umgrenzten an den Linsenåquator nabe herangerückten stelle der Corona ciliaris erfolgt. unter Ausschluss des gesamten weit ausgedehnten Orbicularteiles des Ciliarkörper's.

Eine besondere hintere Kammer scheint im lebenden Tier nicht zu bestehen; an den Schnitten kann sie durch Zugrundegeben der starken vordersten Zonulafasern vorgetauscht werden.

Auf den ersten Blick erkennt man eine gewisse Differenz in dem Verbalten der Zonula auf der temporalen und nasalen Seite: temporal sind die Fasern kräftiger, nasal feiner, jedoch etwas dichter angeordnet, was schon bei schwacher Vergrösserung deutlich hervortritt.

Am stärksten sind auf beiden Seiten die vordersten Zonulafasern; sie weisen eine ungemein grobe Beschaffenheit auf und 
verlaufen in weiteren Abständen voneinander als die weiter binten folgenden. Sie entspringen am medialen Abhang des leicht wulstig hervorspringenden Corona ciliaris-Gebietes und gehen als starke. glatt konturierte, straffe Fasern zu der Gegend der Linse, die sich etwas vor dem Äquator befindet. Unmittelbar vor der Linse teilt sich jede Fasel pinselförmig in ein Bündel feinerer Fasern. was funktionell den Vorteil hat, dass hierdurch eine deformierende Wirkung durch den Zug der einzelnen Zonulafasern auf die Linsenobertlache vermieden wird. Auch ihr retinaler Ursprung erfolgt mit feineren Fibrillen, die sich aber bald zu den' groben Fasern konzentrieren. Nach der Linse hin zerfallen die vordersten groben Fasern nur in gröbere $̈$ iste. Je weiter wir nach hinten gehen. und je feiner die Zonulafasern werden, um so feiner und reichlicher wird auch diese pinselförmige Verastelung.

Nach hinten zu nehmen die Zonulafasel'n allmăhlich eine feinere Beschaffenheit und dichtere Anordnung an, zugleich kommt auch eine gewisse plexusförmige Anordnung zur Beobachtung. Die lentikulare Teilungsstelle der einzelnen Fasern rückt allmählich weiter von der Linse weg, so dass die Teilung nicht mehr pinselförmig genannt werden kann, sondern das Teilungsbündel die Form eines lang ausgezogenen Dreieckes erkennen lässt mit etwas stärkeren Randfasern und im Innern sich plexusartig schief durchkreuzenden und gegen die Linse allmahlich feiner und dichter werdenden Fasern. Zugleich lassst sich nachweisen, dass die einzelnen Faserprodukte der Teilung gegeneinander. nicht isoliert verlaufen, sondern durch ausserordentlich zarte, schief und quer verlaufende Seitenaste in anastomotische Verbindung miteinander treten. Auch nach der Netzhaut hin ist die Teilung der Fasern jetzt eine ausgesprochenere, doch besteht das Teilungsbündel durchaus nicht aus so zarten Ästen, wie lentikular. Über das feinere Verhaltnis der Zonulafibrillen zu dem Ciliarepithel geben meine Prăparate keinen Aufschluss, nur das eine lăsst sich aus der Dichtigkeit der inserierenden Fibrillen folgern, dass die Fasern gleichmăssig die ganze Oberfläche und nicht nur die interzellulären Grenzlinien für ihre Allheftung in Anspruch nehmen.

Bei Betrachtung des Zonulafaserbündels fallt noch auf, dass dieses Bündel an den Schnitten nicht in der Richtung der Äquatorialebene der Linse an letztere herantritt, sondern schief von vorn 
nach hinten unter Bildung eines Winkels von etwa $30^{\circ}$ mit letzterer. Es dürfte sich mit diesem Umstand die von Beer ${ }^{1}$ ) für verschiedene Eidechsen festgestellte physiologische Tatsache in Zusammenhang bringen lassen, dass die Akkomodation bei diesen Tieren nicht durch Gestaltsveranderung, sondern durch Vorwärtsverlagerung der Linse bewirkt wird.

Als besondere Erscheinung sehen wir bei Lacerta, dass das Gebiet der eigentlichen Zonula nach hinten nicht bis zur sogenannten vorderen Grenzschicht des Glaskörpers reicht, sonderı ein breiter Zwischenraum zwischen beiden frei bheibt. Dieser Raum ist abel nicht leer, sondern von einem lockeren Fibrillennetz ausgefüllt, das seiner ganzen Beschaffenheit nach als Glaskörper anzusprechen ist. Es entbehrt jeder Regelmässigkeit in der Anordnung seiner Fibrillen und ist vorn und hinten am dichtesten, in der Mitte am lockersten. Nur vorne ist in diesem Fibrillenkomplex ein aus einigen Fasern bestehendes linsenwärts gerichtetes System nachzuweisen, das bei der Akkomodation eventuell noch eine gewisse Rolle spielen kann. Nasal erscheint dieses retrozonulare Fibrillengeflecht feiner und dichter als temporal, hier schliesst es sich in seiner Beschaffenheit vollkommen dem sonstigen Glaskörper an.

Ein intermediäres Fibrillennetz zwischen den Zonulafasern. wie es bei Frosch und Salamandra vorhanden ist, ist hier nicht nachzuweisen. Jedoch finden sich auch hier hie und da feine Fibrillen, die ohne jede bestimmte Verlaufsrichtung zwischen den Zonulafasern dahinziehen. Auch sind die Zonulafasern an einigen Stellen durch feine Seitenaste miteinander verbunden.

Die "vordere Grenzschichte des Glaskörpers" kommt auf beiden Seiten, nasal und temporal, nicht in gleicher Schärfe zur Ausprägung. Dem soeben Gesagten zufolge verdient sie hier eigentlich nicht den Namen einer Grenzschichte, indem sie angesichts der Gegenwart des soeben geschilderten retrozonulären Fibrillengeflechtes - eigentlich noch in nerhal b des Glaskörpers und nicht an dessen vorderer Grenze ibre Lage hat. Ibre Aufgabe dürfte - abgesehen von einer möglichen Wirkung auf die Lymphzirkulation - auch hier, wie bei anderen Tieren, die sein, zu verhindern, dass bei der Akkomodation und vielleicht auch

1) Th. Beer: Die Akkomodation des Auges bei den Reptilien. Pflügers Arch. f. d. ges. Phys., Bd. 69, 1898. 
bei der Zusammenpressung des Auges durch die Wirkung der äusseren Augenmuskeln der eigentliche Glaskörper in das Gebiet der Zonula hineingedrängt wird.

Ihre retinale Anheftungsstelle findet die Grenzschichte ziemlich weit vor der Ora terminalis, etwa in der Mitte des lang ausgezogenen Ciliarkörpers, ihr lentikulares Ende nicht weit hinter der Ansatzstelle der bintersten Zonulafasern, mit denen die Grenzschichte nicht parallel lauft, sondern so, dass sie an der Linse in einem spitzen Winkel miteinander zusammentretten. Auch hier zerfält die Grenzschichte in der unmittelbaren Nahe der Retina, unter Schwund der dichteren interfibrillåren Substanz, in ihre Fasern.

Die Grenzschichte ist ziemlich dick, aber nach vorn und hinten nicbt allzu stark abgegrenzt, mehr nur als verschwommene streifenförmige Verdickung des Glaskörpers, denn als richtige Membran erscheinend.

Ihr innerer Bau lasst erkennen, dass es hauptsächlich das Auftreten einer verdichteten interfibrillaren homogenen Substanz ist, der sie ihre Entstehung ver'dankt, wobei allerdings die Frage offen gelassen werden muss, ob auch nicht diese scheinbar interfibrillare Substanz aus der Verklebung und scheinbaren Homogenisierung von Fibrillenkomplexen entstanden ist.

Wie gesagt, ist die Grenzschichte an beiden Seiten, nasal und temporal, nicht in derselben Weise entwickelt. Nasal ist sie kaum ausgeprägt. Hier ist gewöhnlich von der ganzen Grenzschichte nur das lentikuläre Ende in Form einer schwachen Verdichtung der interfibrillären Substanz vorbanden. Abgesehen von dieser Stelle hängt also der Glaskörper mit der Zonula in innigster Weise zusammen. Es ist auffallend, dass bei den Amphibien und Reptilien gewöhnlich die nasale Grenzschichte die schwachere ist. I)ieser Ümstand könnte vielleicht über die Rolle der Grenzschichte einigen Aufschluss geben. Wöglicherweise hängt diese Asymmetrie mit der asymmetrischen (temporalwărts verschobenen) Einptlanzungsweise des Sehnerven zusammen.

In den Verbältnissen des Glaskörpers wird unsere Aufmerksamkeit sofort durch ein Verhalten gefesselt, wie es uns schon bei Coluber vivax entgegentrat: durch die Trennung des Glaskörpers in einen inneren trichterförmigen und einen peripherischen Teil. Als Grenze beider Abteilungen erscheint eine membranartige Verdichtung des Glaskörpers, die ringsum in der 
Umgebung der Basis des Zapfens entspringend schief nach vorn und aussen zieht, um unter geradlinigem, nur zuletzt leicht nach aussen gebogenem Verlauf in einiger Entfernung vor dem Übergang der Pars optica in die Pars coeca retinae entsprechend dem hinteren Teile des Ciliarkörpers ihr Ende zu finden. Gewöbnlich kann man aber diese Membran nicht bis an den Ciliarkörper verfolgen, indem sie sich in der Regel schon etwas früher fast unmerklich verliert. Wabrend ihres Verlaufes pflegt sich die Membran im Niveau des vordelen Endes des Zapfens etwas aufzulockern. Auch gallz hinten an ihrem peripapillären Crsprung verliert die Membran gewöhnlich ihren scharf gezeichneten Clarakter, sie lockert sich hier etwas auf. In der Zusammensetzung der membranartigen Verdichtung spielen longitudinale Fasern die Hauptrolle, hinten etwas lockerer stehend, nach vorn mehr und mell. zusammengedr"ungt, überall untermischt mit zirkulär verlaufenden, den Trichter kreisförmig umfasșenden Fasern und in der ganzen Ausdehnung des Trichters, besonders aber in dessen vorderer Abteilung, in regem Wechselverhältnis stehend mit den benachbarten Fasersystemen. Besonders deutlich kommen die longitudinalen Fasern an der hinteren Anheftungsstelle del Membran zur Beobachtung.

Auf der temporalen Seite scheint sich die Grenzmembran in ihrer vorderen Abteilung zu verdoppeln durch Auftreten einer einwärts von ihr liegenden Parallelmembran von gleich starker oder noch starkerer Beschaffenheit. Diese Nebenmembran entspringt etwas vor der ciliaren Anheftungsstelle der eigentlichen Grenzmembran - oder richtiger, der Stelle, wo sich die Fortsetzung der Grenzmembran anheften würde, wenn sie bis zu dem Ciliarkörper nachzuweisen wäre - und läuft nach hinten, nicht ganz die Vitte einhaltend zwischen äusserer Grenzmembran und vorderer Grenzschicht des Glaskürpers, indem sie zur ersteren etwas näher liegt. Weit lässt sich aber die accessorische Vembran nicht verfolgen; in der Höhe des vorderen Zapfenendes sehen wir sie gewöhnlich sich auflösen. Auf der nasalen Seite scheint diese Nebenmembran zu fehlen oder nur in Spuren vorhanden zu sein.

Der Unterschied zwischen dem extra- und intrainfundibulären Teil des Glaskörpers ist in die Augen springend und besonders bei der Betrachtung mit schwacher Vergrösserung zu sehen. 
Die Glaskörperfibrillen der Pars extrainfundibularis sind. mit starker Linse betrachtet, den Fibrillen des Tropidonotus seh" ăhnlich (Textfig. 6). Wir finden hier dieselben verhaltnismässig starken, scharf hervortretenden Fasern, die untereinander in Stărke und Beschaffenheit kaum Verschiedenheiten aufweisen. Der anastomotische Zusammenhang der Fasern ist hier auch kaum nacl:zuweisen.

Der extrainfundibulare Teil zeigt eine Annaherung an die analogen Verhăltnisse bei 'Tropidonotus, doch sind auch grösserc

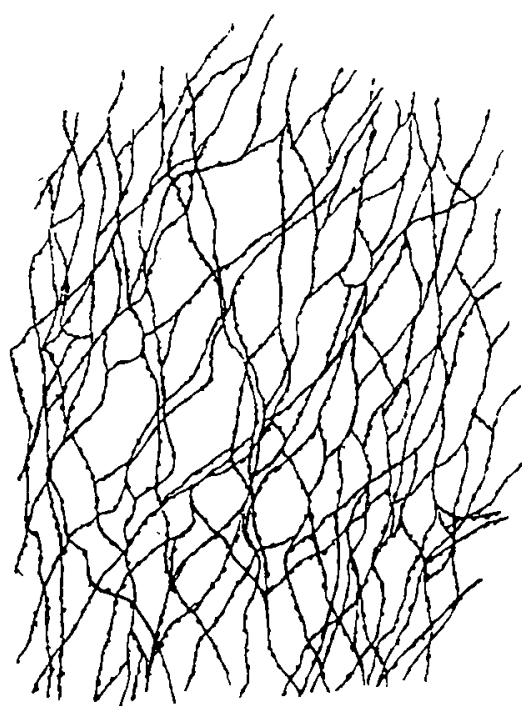

Fig. 6. Lacerta viridis. Aus dem peripherischen Teil des Glaskörpers. Fibrillen mit kleinen Varikositäten (Niederschiäge aus der Interfibrillärsubstanz). Immersion.

Unterschiede vorhanden. so vor allem die Gegenwart eines auffallend locker gefügten Gebietes unmittelbar in der Umgebung des hinteren, retinalen, sich verschmälernden Abschnittes des Glaskörpertrichters. Auf dem Meridionalschnitt erscheint diese lockere Partie in f'orm eines ovalen, hellen, man könnte beinahe sagen vakuolenartigen Gebietes, und zwal zeigt das Gebiet eine grössere Ausdehnung nasal als temporal. Eine bestimmte Anordnung der Fibrillen lässt sich in diesem lockeren Abschnitt nicht nachweisen, es liegt vielmehr ein gleichmässiges Netz vor, allerdings mit sehr ungleichmässig weiten Maschen. Ich möchte nicht verfehlen, auf die interessante l'atsache hinzuweisen, dass diese helle vakuolisierte Partie des Glaskörpers nach meinen Erfahrungen bei keinem anderen Reptil in die Erscheinung tritt, wohl aber bei Rana, und zwal ungefahr an derselben Stelle und in derselben Form, allerdings aber in etwas grösserem limfang.

Was noch extrainfundibular vom Glaskörper übrigbleibt, zeigt eine ziemlich regelmässige Anordnung; allerdings ist diese Regelmissigkeit viel ausgesprochener temporal als nasal. 
Temporal sehen wir dieselben Fasersysteme, die schon bei Tropidonotus beschrieben wurden. Unmittelbar hinter dem ciliaren Ansatz der vorderen Grenzschichte, in dem Winkel zwischen dieser und der Ora terminalis, besonders aber zwischen Ora terminalis und der trichterförmigen Membran, haben wir zunächst ein regelloses Geflecht, ohne bestimmt hervortretende Faserrichtungen, aus groben und feineren Fibrillen bestehend und stellenweise sich zu knotenförmigen Kreuzungsstellen konzentrierend.

Aus diesem regellosen Geflecht der Fasern geht nach hinten, zwischen der Retina und der trichterförmigen Membran, ein Faserstrom aus, dessen Elemente im allgemeinen die l'endenz haben, nach einwärts und hinten auszustrahlen. Hierbei bilden die Fasern keine stärkeren zusammenhängenden Bündel, sondern laufen mit Vorliebe einzeln, so dass die regelmässige Verlaufsrichtung nicht nur bei schwacher Vergrösserung, sondern auch bei starkerer zur Ansicht liommt, bei letzterer eigentlich noch besser als bei ersterer, abweichend von den Verhallnissen bei anderen Tieren, z. B. bei Salamandra. Das Fasersystem kommt auch hier gerade nur bei einer bestimmten Schnittrichtung in seiner vollen Regelmässigkeit zur Anschauung; natürlich ist für jede Stelle des ringsum an der Ora terminalis entspringenden Systems diese Schnittrichtung eine andere.

Wan kann an dem ganzen System drei Faserrichtungen unterscheiden. Die eine Richtung ist die sich der ausseren Grenzbaut des Trichters anschliessende. Ton einer unmittelbar vor der Ora terminalis gelegenen Stelle der Pars coeca entspringend, geht diese Fasergruppe schief an die genannte Grenzhaut heran, um sie etwas vor ihrer mittleren Abteilung zu erreichen; der grösste Teil der Fasern verliert sich hier, ein kleinerer Teil zieht dicht neben der Grenzhaut, parallel mit ihr, einwarts von der lockeren Glaskörperstelle nach hinten.

Die zweite Faserrichtung ist die mit der Netzhaut parallele, tangentiale. Diese Fasergattung schliesst sich sehr regelmässig der Innenfläche der Pars optica an und lässt sich zum Teil hinter der beschriebenen lockeren Partie bis in die Năhe der Sehnervenpapille verfolgen.

Ein drittes System kreuzt sich schief mit beiden Faserrichtungen. Es sind das Fibrillen, die, von der Ora terminalis und der ibr nahe gelegenen Partie der Pars optica entspringend, 
unter leicht bogenförmigem Verlauf schief nach den vorderen 'Teilen der Infundibularmembran ziehen, wobei sie sich natürlich zunăchst mit den peripherischsten Tangentialfasern, weiter einwarts aber auch mit den an erster Stelle erwahnten, weniger schiefen Fasern kreuzen müssen. Die sich kreuzenden Fasern umschliessen regelmässige rhombische Felder, die mit starken Vergrösserungen sichtbar sind.

Neben allen diesen Fasern scheint auch eine äquatorial und paraaquatorial verlaufende Faserrichtung vorhanden zu sein, allerdings wenig ausgesprochen.

Die nasale Seite der Extrainfundibularabteilung unterscheidet sich von der beschriebenen temporalen bloss dadurch, dass die geschilderten Systeme, wenn auch vorhanden, alle weniger ausgesprochen sind, daher das ganze Bild weniger regelmassig erscheint. Das an erster Stelle erwăhnte schief zur Trichtermembran ziehende System ist bedeutend schwächer und schmaler als temporal, das peripherische tangentiale System hört schon früher auf; die geschilderten Kreuzungen sind weniger ausgesprochen.

Das Innere des Glaskörpertrichters weist sehr bemerkenswerte Verhältnisse: auf. Es gibt vielleicht kein zweites Beispiel im Tierreich für eine derartige regelmässige Anordnung der Glaskörperfibrillen. Die Achse des Trichters wird, wie schon beschrieben, von dem Zapfen gebildet, der aber nicht ganz bis zur Linse reicht. Entsprechend den Seitenteilen des Zapfens entspringt in dessen ganzer Lange ein Fasersystem, teilweise direkt an der Obertäche des Zapfens sich inserierend, teilweise bei genauerer Betrachtung - in der Umgebung des Zapfens aus einem Fibrillennet $z$ sich herausbildend, dessen Fasern sehr regelmassig divergierend parallel mit der ausseren Trichtermembran nach aussen und yorn ziehen, in ungefälı gleichen Abständen voneinander angeordnet. Die innersten dieser Trichterfasern erreichen die Linse, an deren Kapsel sie inserieren, die weiter nach aussen folgenden, d. b. weiter hinten entspringenden Fasern endigen im Bereich der vorderen Grenzschichte des Glaskörpers, teils indem sie sich schon vor der Grenzschichte verlieren, teils indem sie sich direkt mit ihr verbinden, teils indem sie sie $\mathrm{zu}$ durchsetzen scheinen, um sich im oben beschriebenen retrozonulären, vor der Grenzschichte gelegenen Fibrillengetlecht zu verlieren. Die aussersten Fasern treten an die Pars ciliaris 
retinae heran, lassen sich aber nicht bis an diese verfolgen, sondern scheinen sich dicht vor ihr aufzulösen. Nasal ist der Verlauf dieses ganzen Fasersystems voru, entsprechend der vorderen Grenzschichte, verschwommener.

Zwischen diesen stărkeren, divergierenden Fasern spinnt sich ein zarteres, subtileres Grundnetz aus, das mit ersteren unmittelbar zusammenhängt.

Vor der Spitze des Zapfens, zwischen diesem und der Linse, grenzt sich ziemlich deutlich ein dreieckiges Gebiet mit vorderer, durch die Linse gebildeter Basis ab, durch seine hellere Beschaffenheit hervortretend, die wieder durch die sehr lockere und regellose Beschaffenheit des hier befindlichen Fibrillennetzes und durch die geringe Zabl der vom Zapfen zur Linse ziehenden Fasern bedingt ist. Ganz fehlen diese keineswegs, ja die vorhandenen zeichnen sich auch durch besondere Starke aus, doch ist ihre Zahl sehr gering und dabei laufen sie auch nicht so regelmässig gestreckt wie die Trichterfasern des Aussengebietes. Auch zeigen sie mannigfach Teilungen, besonders in der Nähe ihrer lentikulären Ansatzstelle. Die hellere Beschaffenheit des geschilderten dreieckigen Gebietes dürfte teilweise auch auf die lichtere Beschaffenheit der Interfibrillarsubstanz zurückzuführen sein.

\section{Schildkröten.}

Zur Untersuchung standen schöne, vollkommen ausgewachsene Exemplare von Testudo graeca zur Verfügung (Fig. 5). Das Auge hat eine eigentümliche, von der Augenform der anderen Reptilien etwas abweichende Gestalt: auf die hintere halbkugelförmige Hălfte des Auges ist die vordere Hälfte als niedriger abgestumpfter Kegel aufgesetzt, mit abgerundetem, durch die gleichmảssig gewölbte Hornhaut gebildetem vorderen Ende. Bie Linse ist auffallend klein, in ihrer Form sich der der Eidechsen nähernd. Ein Orbiculus und eine Corona ciliaris sind, besonders an der temporalen Seite, kaum zu unterscheiden, der Ciliarkörper geht fast unmerklich in die kurze, dicke Iris über, auf deren vordere Fläche sich weit hinein das machtig entwickelte Netzwerk der Spongiosa anguli camerae anterioris erstreckt. Ein betriichtlicher Teil der Pars coeca retinae entspricht dem Glaskörper, indem sich die Ansatzstelle der vorderen Grenzschichte erst in ziemlich grosser Entfernung vor der Ora terminalis be- 
findet. Die Sehnervenpapille stellt sich als tellerförmige Vertiefung ohne Polster, Wulst, Zapfen oder dergleichen dar. Auch innere Augengefässe fehlen. Glaskörper und Zonula zeigen einen höheren Typus als bei den übrigen Reptilien, wenn man als Maßstab der Beurteilung den grösseren oder geringeren Abstand von der Struktur der analogen Bildungen im Auge der Säugetiere berücksichtigt.

Der Glaskörper scheidet sich durch eine ziemlich scharf ausgeprägte Grenzschichte von dem davor liegenden Zonularaum ab. Die Crrenzschichte beginnt ungefăhr in der llitte des Ciliarkörpers oder an einer Stelle, die etwas hinter der Mitte liegt und zieht in ziemlich geradlinigem Verlauf zu dem seitlichen Abschnitt der binteren Linsentläche. Temporal ist sie etwas stärker als nasal und lässt sich ciliarwarts fast bis an die Pars coeca retinae verfolgen, wïlurend sie nasal etwas schwächer ist und sich schon in einiger Entfernung vor dem Corpus ciliare verliert. An der temporalen Seite ist sie oft eine kürzere oder lïngere Strecke doppelt und zeigt auch, besonders am lentikulären Ende, Verzweigungen.

Die Zonula weist einen Zustand auf, der auffallenderweise als niedriger stehend bezeichnet werden kann als der bei den anderen Reptilien beschriebene, indem neben den eigentlichen Zonulafasern jenes feine interstitielle Fibrillennetz, wie es bei den Amphibien vorliegt, vorbanden ist.

Die eigentlichen Zonulafasern entspringen von der ganzen Obertache der Retina ciliaris, mit Abrechnung ihrer hintersten Abteilung, die schon dem Bereich des Glaskörper's entspricht. Sie ziehen in gestrecktem, beinahe parallelem, nur ganz leicht divergierendem Verlauf $\mathrm{zu}$ den aquatorialen und paräquatorialen Teilen der Linse hin. Ihre Anordnung ist eine weniger dichte als bei Tropidonotus und Lacerta.

Bei der Schildkröte gibt es ebenfalls keine Processus ciliares. Diese werden hier durch eine niedrige, zusammenhängende zirkuläre Erhebung des Corpus ciliare vertreten, die temporal noch bedeutend schwächer ist als nasal, so dass sie hier kaum walurnehmbar ist; das Epithel dieses Wulstes ist in seiner ganzen Ausdehnung, d. h. auch im Bereiche seines vorderen Abhanges nur in seiner tieferen Schichte pigmentiert. Der Wulst liegt gerade gegenüber dem Linsenăquator. 
Die Zonulafasern, die vom Wulst entspringen, gehen unter ctwas stärkerer Divergenz und verhältnismässig dichterer Anordnung in der Hauptsache zum Linsenäquator und zu einem vor diesem gelegenen Gebiet der Linsenkapsel; nur wenige endigen linter dem Äquator, welche sich dann in ihrem Verlauf mit den weiter hinten entspringenden Fasern kreuzen. Die vordersten lieser vom Ciliarwulst entspringenden Fasern zeigen schon einen unmittelbaren Anscbluss an die hintere Iristläche, so dass ron ciner faserfreien hinteren Kammer-hier nicht die Rede sein kann.

Die hinter der kleinen Eminentia ciliaris entspringenden Fasern sind etwas lockerer angeordnet und lassen einen beinahe parallelen Verlauf erkennen. Ihr Ansatz erfolgt in einem Gebiet schon etwas hinter dem Äquator; von ihrer Kreuzung mit den weiter vorn entspringenden Fasern war schon oben die Rede. Bevol sie die Linsenkapsel erreichen, zerfallen sie, ebenso wie die von der Eminentia entspringenden Fasern, pinselförmig in feine Fibrillen. Nach hinten $z \mathbf{u}$ wird diese terminale Auflösung der Hasern spärlicher.

Die Fasern zeigen im ganzen Beleich der Zonula Veristelungen, wobei sich die Vebenäste mit analogen Ästen der benachbarten Fasern verbinden und zu stärkeren Fasern vereinigen. Auch sehen wir nicht selten quere oder schiefe Verbindungszweige zwischen den benachbarten Stammfasern.

Zwischen den Zonulafasern spinnt sich, wie schon erwähnt, das zarte fibrilläre Grundnetz der Zonula aus, ähnlich wie bei den von mir untersuchten Amphibien. Nur ist bier dieses Netz nicht in demselben Yaße entwickelt wie beim Frosch und beim salamander. Auch hier zeigt dieses Netz überall eine kontinnierliche Verbindung mit den eigentlichen Zonulafasern.

Die hintere Abgrenzung des Zonularaumes durch die vordere Verdichtungsschichte des Glaskörpers zeigt in einer Beziehung einen Cnterschied auf beiden Seiten, temporal und nasal. Temporal bält sich der Verlauf dieser Schichte an die Richtung der hintersten Zionulafasern, an die sie sich unmittelbar anschliesst. Nasal dagegen weicht sie von dieser Richtung $a b$, indem sie sich nur in ihrer lentikulären Abteilung an die hintersten Fasern anschliesst, ciliarwärts dagegen sich von ihnen allmählich etwas nach hinten entfernt, so dass zwischen den hintersten Fasern und der genannten Schichte ein schmaler, dreieckiger, mit der Basis nach 
aussen gerichteter Zwischenraum entsteht; der von einem nicht allzu dichten Fibrillennetz ausgefüllt wird, ohne bestimmte Orientierung der Fibrillen. Ab und zu lässt sich übrigens dieses Yèrhalten auch an der temporalen Seite nachweisen. Schliesslich sei bemerkt, dass die bintersten Zonulafasern manchmal nicht bis zur Linse verfolgt werden können, sondern schon früher mit der Grenzschichte des Glaskörpers verschmelzen, ähnlich wie dies nach den Beobachtungen v. Lenhosséks ${ }^{1}$ ) auch bei den Fögeln vorkommt. Ich habe dieses Verbalten nur auf der temporalen Seite beobachtet.

Die Glaskörperfibrillen erscheinen im allgemeinen zarter und von gewundenerem Verlauf als bei den Sauriern und Ophidiern; die stärkeren, selbständigeren Züge der Glaskörperarchitektur werden nicht durch stäliere Einzelfibrillen, sonderı durch zusammenhängende Bündelchen zarter Fibrillen gebildet. Es sind das Verhaltnisse, durch die sich der Chelonierglaskörper dem der Säuger nahert.

Eine sehr auffallende Erscheinung ist der wohlentwickeltè, scharf begrenzte Canalis liyaloideus, natürlich auch wieder nur als eine besonders strukturierte axiale Glaskörperabteilung, also als Tractus hyaloideus und nicht als eigentlicher Kanal mit freiem Lumen ausgeprågt. Er nimmt mit seinem Ursprunge die ganze Breite der ausgehöhlten Sehnervenpapille in Anspruch. Auf dell Anfang folgt zunăchst eine leichte Erweiterung des Kanales, bald aber eine Verschmalerung, die anfangs stärker, dann sukzessive schwächer vor sicl gehend beinahe bis an das vordere Ende des Kanales anhält, zuletzt aber doch wieder einer geringfügigen Erweiterung Platz macht. Die weiteste Stelle des Kanales befindet sich also etwas vor der Papille, die schmälste vor der vorderen Endigung. Dieser Wechsel des Lumens ist insofern interessant, als el auch am Canalis hyaloideus der Säuger, z. B. beim Schwein, ${ }^{2}$ ) in derselben Form wiederkehrt, allerdings in viel ausgesprochenerer Weise, so dass man von einer hinteren Ampulle. einem schmalen Mittelstück, einem mehr nach vorn gelegenen

1) M. v. Lenhossék: Die Entwicklung und Bedeutung der Zonulafasern nach Lntersuchungen am Hühnchen. Arch. f. mikr. Anat., Bd. 7i, 1912, S. 28 , cfr. S. 286.

3) Siehe A.v. Szent-Györgyi: Der Canalis hyaloideus im Auge des Schweines. v. Gra efes Archiv, 85, 1913. 
Isthmus und wieder von einer vordersten Erweiterung reden kann. Das geschilderte Verhalten des Lumens scheint also typisch $z u$ sein.

In einer Beziehung liegt aber ein bemerkenswerter Unterschied gegenüber den Säugern vor: der Kanal läuft nicht in der Richtung zur hinteren Linsenfläche, sondern temporal davon in der Richtung des Zwischenraumes zwischen Linse und Ciliarliörper; el lässt sich bis direkt an die Grenzschichte des Glaskörpers verfolgen, um in der Nähe der Linse an ihr zu endigen.

Auffallend ist auch der gestreckte, geradlinige Verlauf des Kanales und seine ziemlich scharfe Abgrenzung durch eine schmale, aber scharf gezeichnete Verdichtungshaut, die, aus longitudinal verlaufenden Glaskörperfibrillen und verdichteter Interfibrillarsubstanz bestehend, als feine Membran ununterbrochen von der Sehnervenpapille bis zur vorderen Grenzschichte des Glaskörpers verfolgt werden kann. Ausgefüllt wird der Kanal durch ein zartes fibrilläres Netzwerk von besonders lockerer Bescluaffenheit, das mit der Schlussmembran unmittelbar zusammenhüngt. Der anastomotische Zusammenhang der Fasern ist hier stark entwickelt. Besonders locker ist das Gewebe im breiteren Anfangsteil des Kanales. Hier ist unter den Fasern die Langsrichtung die vorwiegende, während in den vorderen Teilen mehr eine Querrichtung der Fasern hervortritt.

Die dem Glaskörper entsprechende Partie der Pars ciliaris retinae ist der Ausgangspunkt besonders hervortretender Fasersysteme.

Wieder ist temporal und nasal zu unterscheiden. 'Tempoial umfassen die Fasern in ihrem Ursprung die Stelle der Ora terminalis und die von hier bis zur Ansatzstelle der vorderen Grenzschichte rcichende Partie des Ciliarkörpers; auch von der Grenzschichte selbst lösen sich einzelne Bündel ab. Zunachst scheint das ganze ribrillensystem einheitlich, ohne besondere Gruppierung. In der unmittelbaren Nähe der Ora terminalis sind die Fasern etwas dichter angeordnet (Retziussches Bündel). Weiter nach hinten abel leitet sich sebr bald eine Trennung des sich nach hinten umbiegenden Faserstromes in einzelne Bündelchen ein, die in zierlich gewelltem, einer Haarlocke ähnlichem Verlauf zum Canalis hyaloideus ziehen, und zwar in bogenförmiger, der hinteren Linsenfläche und der inneren Setzhauttlache konzentrischer AnArchiv l.mikr. Anat. Bd. 8ś. Abt. I. 
ordnung. Einzelne Bündel treten starkel als die anderen hervor. Nur an der vordersten Partie des Glaskörpers hinter der vorderen Grenzschichte gibt es keine so regelmässige Anordnung. Hier finden wir nur einzelne, ganz unregelmässig verlaufende Bündel, die hinter der Grenzschichte von der ciliaren Retina entspringen oder sich schon von der Pars optica retinae ablösen. In dem hinter dieser Partie gelegenen Glaskörper bieten die zarten Wellenfiguren, mit stårkeren Vergrösserungen betrachtet, ein ausserordentlich zierliches Bild dar, dessen genaue bildliche Darstellung nur auf dem Wege der Mikrophotographie denkbar ist.

Das-Schicksal dieser Bündel ist verschieden. Ein 'T'eil verliert sich unter allmüblicher Auflockerung schon in einiger Entfernung vom Kanal. Ein anderer erreicht den Tractus hyaloideus. Diese Bündelchen unterliegen, an der Wandung des Kanales angelangt, einem verschiedenen Schiclisal. Der grösste Teil scheint sich mit der Wandmembran zu verbinden und damit sein Ende $z u$ finden, ein anderer Teil umkreist von der Seite den Kanal und schligt sich auf die andere Seite hinüber, wo er sich im Glaskörper verliert. Wieder andere Bündel lenken dicht an der Kanalwandung mit kühner Biegung nach hinten um und lassen sich, längs des Kanals verlaufend, bis in die Nithe der Netzhaut verfolgell. Natürlich muss man sich, um diese Verhaltnisse zu studieren, nëben den Meridionalschnitten auch aquatorialer Schnitte bedienen.

Zwischen diesen konzentrischen Bündelchen schalten sich in der hinteren Halfte des Auges weitere konzentrische Fasergruppen ein, die mit der Wandung des Canalis hyaloideus in Zusammenbang stehen, und von ihr ausgehend konzentrisch, der Form der Netzhautoberflache folgend, nach vorne ziehen, um sich im Glaskörper in einiger Entfernung von dem Tractus hyaloideus zu verlieren. Diese Bildungen, die nur aus etwas dichter angeordneten Fasern bestehen, sind besonders an der nasalen Seite gut entwickelt. Sie bilden aber bei weitem keine so auffallende Erscheinung, wie die an erster Stelle erwăhnten Fibrillenbündel.

Eine weitere Besonderheit der temporalen Seite gegenüber der nasalen ist, dass sich hier stellenweise von hinten nach vorn ziehende, ungefïhr in der Verlaufsrichtung des Canalis hyaloideus gelegene Fasern nachweisen lassen, die sich natürlich mit den konzentrischen Systemen ungefăhr rechtwinklig kreuzen. Sie 
stehen mit den umgebenden lasern teilweise in innigerem $\mathrm{Zu}$ sammenhang, teilweise sind sie aber auch ganz unabliangig von ihnen. Nach hinten zu verlieren sie sich unmerkbar, ohne die Netzhaut $z u$ erreichen. Wan könnte sie mit den radiären liasern bei Tropidonotus vergleichen, wenn sie nicht gerade auf der entgegengesetzten Seite ihre Lage hätten; bei Tropidonotus finden sich nämlich die fraglichen Fasern mehr auf der nasalen Seite. Eventuell könnte man sie auch mit den Fasern des Retziusschen Systems des Salamanders vergleichen.

Nasal ist das Bild nicht unbetrachtlich verschieden. Die Fasern, die am vordersten Teil der ciliaren Retina dicht hinter der volderen Grenzschichte des Glaskörper's entspringen, ziehen in ziemlich gedrångtem Verlauf, beinahe ein ganz isoliertes Bündel bildend, in unmittelbarem Anschluss an die vordere Grenzschicht bis hinter die peripherischen Teile der Linse, lenken hier bogenförmig um, um sich in den zentralen Teilen des Glaskörper's zu verlieren. Anfangs verlaufen die Fasern ganz geradlinig, in ihrer letzten Abteilung, wo sie sich auflockern, nehmen sie aber einen auffallend ondulierten Verlauf an.

Weiter hinten, unmittelbar vor der Ora terminalis, entspringt ebenso wie temporal ein breiter, sich bald nach hinten krümmender Faserstrom, aus wellig verlaufenden, sich zu kleinen haarlockenartigen Bündeln gruppierenden Fasern bestehend. Während sich aber temporal dieser Faserstrom, wie wir hörten, bald in konzentrische Faserlamellen sondert, unterbleibt hier diese Differenzierung. In dieser Fasergruppe ist das Retziussche Bündel schon mit Sicherheit zu erkennen.

Eine konzentrische Anordnung lässt sich allerdings auch auf dieser Seite im Glaskörper nachweisen, doch ist sie nicht so regelmässig, wie temporal; das konzentrische Gepräge erhält der Glaskörper nicht durch hervortretende Faserbündel, sondern mehr durch die ähnliche Verlaufsrichtung einzelner Fasern.

Dicht hinter der Linse lässt sich im allgemeinen eine mit der hinteren Linsenflache parallele Faserrichtung nachweisen.

Der konzentrischen, dichteren Fasergruppen, die vom Kanal ausgehend, sich peripherwärts auflösen, ist schon Erwähnung getan worden.

Eine besondere Membrana hyaloidea ist auch hier nicht nachzuweisen, wohl aber ist eine geringfügige Verdichtung des 
Glaskörpergewebes an seiner Oberthäche unverkennbai vorhanden. indem dicht an der Netzhaut eine gedrangtere Gruppierung der hier besonders feinen, parallel mit der inneren Obertläche der Setzhaut verlaufenden Fibrillen vorhanden ist.

\section{Vergleich der im Glaskörper hervortretenden Strukturen bei Amphibien und Reptilien.}

Wir haben bei Anuren und Urodelen am Sehnervenkopf ein starkes. nach vorn divergierendes, in der Richtung der Linse ziehendes Faserbündel entspringen sehen, dem wir dann auch in der Klasse der Reptilien bei Tropidonotus natrix in ziemlich gleicher Form begegneten. Bei einem andelen Ophidier; bej Coluber vivax, ergab sich als einziger Unterschied die Ausbildung einer Art trichterförmiger Grenzmembran als ausserer Abschluss dieser Fasergruppe, welch letztere wir als Tractus centralis corporis vitrei bezeichneten.

Eine neue Bildung - bei den Amphibien noch feblend erscheint bei Tropidonotus. Es ist dies ein sich unmittelbar diesem Tractus anschiliessendes, aber doch selbständiges, ebenfalls in der axialen Gegend des Glaskörpers gelagertes Faserbündel, das sich von dem Tractus centralis einerseits durch seinen Ursprung unterscheidet, indem es nicht unmittelbar vom Sehnervenliopf, sondern unabhängig davon von einem Ast der Art. centralis retinae entspringt, andererseits aber dadurch, dass es die Eigenart zeigt, dass es zwischen seinen kraftigen Fasern ein ausserordentlich lockeres und zartes Fibrillennetz in sich schliesst, wodurch dieses Bündel trot $z$ seines Gehaltes an peripherischen stärkeren Fasern innerhalb des Glaskörpers als hellere Strasse hervortritt. Wir haben hier die ersten Spuren eines "Canalis" oder "Tractus hyaloideus" vor uns, der uns dann bei Coluber vivax in etwas deutlicherer Form entgegentritt.

Bei Testudo fallt die eine von den beiden beschriebenen Bildungen, namlich der Tractus centralis, weg, dafür sehen wir einen wohlentwickelten Tractus hyaloideus, dessen Beziehungen zu dem Gefässast jedoch nicht mehr erkenubar sind, da der betreffende Ast mit den übrigen Glaskörpergefässen zusammen vollkommen geschwunden ist. Der Tractus hyaloideus hat infolgedessen einen neuen Ansatz gefunden, und zwar an der Sehnervenpapille; es hat sich damit das Verhalten eingeleitet, das wir auch 
bei den Säugetieren finden. Auch bei Coluber caspius sehen wir schon etwas ähnliches, mit dem Unterschied nur, dass der neue Ansatz infolge der Gegenwart eines "Zapfens" an diesem erfolgt, und zwar an einer Stelle, die sich von dessen Spitze nicht weit entfernt befindet.

Bei Lacertiden bleibt es dem subjektiven Ermessen überlassen, ob man das auffallend lockere dreieckige Gebiet zwischen der Spitze des Zapfens und der binteren Linsenfläche als ein Homologon des 'I'ractus hyaloideus auffassen soll. Dafür spricht, dass bei Vögeln der Tractus hyaloideus ebenso von der der Linse am nachsten gelegenen Randpartie des Pecten entspringt.

Der Ursprung des Tractus centralis erfährt durch das Auftreten eines Zapfens naturgemäss eine Verlagerung auf diesen letzteren, und zwar nicht auf dessen Spitze, sondern auf dessen seitlichen Cmfang von der Spitze bis zu seiner Basis. Yit diesem Ursprung diirtte auch das abweichende Ausseben des Tractus centralis bei den mit starkem Zapfen versehenen Tieren, wie Lacerta, zusammenhängen. Das eigenartige trichterförmige innere Glaskörpergebiet bei Lacerta ist meiner Ansicht nach nichts anderes als ein stark entwickelter Tractus centralis, gegen die übrigen T'eile des Glaskörpers, ebenso wie bei Coluber vivax, durch eine besondere Grenzmembran geschieden.

Schon in der Einleitung habe ich es versucht, über die Bedeutung der im Glaskörper nachweisbaren konstanten Strukturen eine Ansicht auszusprechen. Ich habe in erster Linie in statischen Aufgaben die Bestimmung derselben erblickt. Daneben kommt aber noch ein zweites Moment in Betracht, das besonders für die Erklärung der membranartigen Differenzierungen innerhalb des Cilaskörpers herangezogen werden darf. Es ist dies die Annalume, dass diese Differenzierungen für den Säftestrom im Glaskörper von Bedeutung sind, indem sie gewisse Bahnen für diesen Strom abgrenzen und ihnen so den Weg weisen. Ich muss mich darauf beschränkell, auf diesen Gesichtspunkt im allgemeinen hingewiesen zu haben, da ich nicht in der Lage bin, genaueres hierüber anzugeben.

Was schliesslich die innerhalb des Glaskörpers befindlichen zellulüren Elemente betrifft, so kann ich hierüber keine aus- 
führlicheren Yitteilungen machen, da die Methoden, deren ich mich bedient habe (Silbermethode, Überfärbung mit molybdänsaurem Hämatoxylin), zur Darstellung der Zellen nicht geeignet sind. Immerhin kann ich angeben, dass ich diese Elemente am zahlreichsten im Cilaskörper der Ophidier gefunden habe, und zwar in der Umgebung der verschiedenen Glaskörpergefüsse. Nach ihrem ganzen Aussehen scheinen sie mir Wanderzellen zu sein, doch fehlen mir die feineren listologischen Beweise zur Sicherstellung dieser Annahme.

\section{Zusammenfassung.}

1. Das fibrilläre Gerüstwerk des Glaskörpers weist bei allen untersuchten Amphibien und Reptilien (und wabrscheinlich bei allen Wirbeltieren) einen besonderen, für jede Spezies charakteristischen Bau auf, der bei demselben Tier in allen Fällen bis in die kleinsten Details regelmassig wiederkeurt.

2. Zonula und Glaskörper sind bei Amphibien und Reptilien nicht so scharf voneinander geschieden wie bei böheren Wirbeltieren. Immerhin ist bei den meisten Formen als Grenze zwischen beiden eine vordere Verdiclıtungsschicht des Glaskörpers, aus stärkeren Fibrillen und verdichteter Interfibrillärsubstanz bestehend, nachzuweisen, die allerdings bei einzelnen Tieren, wie z. B. bei Lacerta, nur in Spuren vorhanden ist. An der temporalen Seite ist sie stärker entwickelt als nasal, wo sie manchmal (Lacerta) ganz fehlt. Auch ist hervorzuheben, dass diese Membran bei einzelıen Tieren nicht unmittelbar Glaskörper und Zonula voneinander trennt, sondern schon im Bereich des Glaskörpers liegt. d. $h$. an beiden Seiten von Glaskörperfibrillen umgeben ist.

3. Die Zonula besteht bei allen untersuchten Amphibien und bei Cheloniern aus zwei Bestandteilen: den eigentlichen Zonulafasern und einem zarten interstitiellen Fibrillennetz. Die Zonulafasern selbst können miteinander in geflechtartiger Verbindung stehen. Das feine Zwiscbennetz zeigt von Tiel zu Tier eine verschieden starke Entwicklung und steht mit den Zonulafasern in unmittelbarer Verbindung. Das grosse Interesse, das sich an die Gegenwart dieses zarten Netzes knüpft, besteht darin, dass wir hier ein bei den höheren Wirbeltieren nur als vorübergehendes embryonales Stadium (zonulärer Glaskörper) vorhandenes Bild dauernd festgehalten sehen. Einer ahnlichen Beurteilung unter- 
liegt bei den Reptilienformen, wo kein solches interstitielles Netz vorhanden ist (Saurier, Ophidier), der verästelte und vermöge vielfacher anastomotischer Verbindungen netzartige Charakter der Zonula, der bei Cheloniern neben dem Vorhandensein des interstitiellen Grundnetzes ausgeprägt ist.

4. Der Glaskörper zeigt überall den bekannten fibrillären Bau mit anastomotischer Verbindung der Fibrillen. Überall ist eine bestimmte Struktur nachzuweisen, indem gewisse konstante Faserrichtungen hervortreten, als Ergebnis einer sekundären Differenzierung, Verdichtung, bestimmten Gruppierung etc. der Fasern. Die Fibrillen des Glaskörpers zeigen die Tendenz, sich sekundär an allen Gebilden, die sich im Glaskörper befinden und die ihn von aussen umgeben, $z u$ inserieren.

5. Mit Ausnalume von Rana ergab sich bei allen untersuchten Tieren ein ziemlich ausgesprochener Unterschied in der Gruppierung der Fasern in der temporalen und nasalen Hälfte des Auges. Es dürfte diese strukturelle Asymmetrie mit der exzentrischen, und zwar bei allen Amphibien und Reptilien temporalwarts verschobenen Eintrittsweise des Sehnerven in das Ange zusammenbängen.

6. Bei Salamandra treten zwei besonder's differenzierte Fasergruppen in die Erscheinung: der vom Sehnervenkopf nach vorn in den Gilaskörper ausstrahlende Tractus centralis und das von der Gegend der Ola terminalis (= serrata) nach einwärts und hinten ziehende, aus ziemlich groben Fasern bestehende Retziussche Fasersystem, das aber nur an der temporalen Seite vorhanden ist. Im übrigen wird der Glaskörper von einem fein gesponnenen Fibrillennetz gebildet, das auf der nasalen Seite eine ziemlich ausgesprochene konzentrische Anordnung erkennen lässt, während temporal diese Anordnung weniger deutlich ist.

7. Bei Rana ist der Tractus centralis ebenfalls eine auffallende Erscheinung. Noch stärker entwickelt stellt sich aber das Retziussche Fasersystem dar, das nunmehr nicht nur temporal, wie bei Salamandra, sondern auf allen Seiten gleichmässig entwickelt vorhanden ist. Sehr charakteristisch ist eine auffallend locker gewebte helle Glaskörperzone, die den Tractus centralis ringförmig umgibt. Im übrigen ist das Fibrillennetz des Glaskörpers lockerer und in seiner Anordnung regelloser als bei Salamandra. 
8. Bei Tropidonotus ist wieder der Tractus centralis die auffallendste Differenzierung innerhalb des Glaskörpers. Jedoch erscheint hier auch ein anderes, neues Gebilde, das trotz seines engen Anschlusses an den genannten Tractus eine morphologisch ganz neue, von diesem unabuängige Bildung darstellt. Es ist dies das als Tractus hyaloideus zu bezeichnende trichterförmige Faserbündel, das von dem temporalen Ast der Zentralarterie entspringend in dichtem Anschluss an den Tractus centralis zur hinteren Linsenfläche zieht. Wir erkennen darin die erste Spur des schon bei Cheloniern zur vollen Entwicklung gelangenden und dann bei Vögeln und Säugetieren festgehaltenen Canalis hyaloideus. Der übrige Teil des Glaskörper's weist ausserdem noch verschiedene andere typische Fasersysteme auf, ron denen besonders ein radiäres, nur auf der nasalen Seite gut entwickeltes System neu ist. Die Fibrillen des Glaskörpers sind im allgemeinen gröber als bei den Amphibien. Das Retziussche Fasersystem fehlt vollkommen.

9. Bei Coluber caspius ragt von der Oberfläche des Selnervenkopfes ein kleiner Zapfen hervor. Der Tractus centralis nimmt von diesem Gebilde seinen Crsprung, ebenso wie auch der Tractus hyaloideus. Im übrigen stimmen die Verbältnisse mit denen bei Tropidonotus überein.

10. Bè Lacerta finden wir ganz besondere Verhälnisse. Hier erscheint del Tractus centralis, der von den Seitentlïchen des mächtig entwickelten Zapfens entspringt, durch eine trichterförmige Membran rom umgebenden Glaskörper getrennt. Der Zapfen reicht nicht ganz bis zur Linse; der Zwischenraum zwischen beiden wird durch eine dreieckige lockere Partie in Anspruch genommen, die vielleicht dem Tractus hyaloideus entspricht. Der ausserhalb des umfangreichen Trichter's gelegene Glaskörperabschnitt ist dem des Tropidonotus sehr ăhnlich, nur fehlen hier die radiären Fasern und ist auffallenderweise rings um den Tractus centralis eine äbnliche lockere Partie vorbanden, wie beim Frosche.

11. Der Glaskörper von Testudo zeigt die meiste Annäherung an das Säugerauge. Ein Zapfen fehlt, die Glaskörpergefässe sind vollkommen geschwunden. Ein Tractus centralis, diese bei den anderen Reptilien und den Amphibien so auffallende Bildung wird lier vollkommen vermisst, dafür zeigt sich der 
Tractus byaloideus in voller Entwicklung, und zwar unter dem Bilde eines rom Sehnervenkopf nach vorn ziehenden, nur ein ganz lockeres Fibrillenwerk in sich schliessenden, nach aussen durch eine Membran ziemlich scharf abgegrenzten Ganges. Die auffallende Armut dieses Ganges an fibrillarem Inhalt rechtfertigt die Bezeichnung "Canalis hyaloideus", obwohl es sich natürlich nicht um einen völlig leeren, mit einem Lumen versehenen Gang handelt. Der Lianal entspringt am Sehnervenkopf, endigt aber nicht an der Linse, sondern temporal davor im \%wischenraum zwischen Linse und Ciliarkörper an der vorderen Verdichtungsmembran des Glaskörpers. In dem ausserhalb des Káanales befindlichen Glaskörper herrscht die konzentrische Anordnung vor, besonders auf der temporalen Seite, wo der Crlaskörper ein System konzentrischer, zum grossen 'T'eile von der Gegend der Ora terminalis entspringender fibrillärer und lamellenartiger Differenzierungen aufweist; weniger ausgesprochen und nicht so regelmassig ist dieses System auf der nasalen Seite. Die Differenzierung lamellenartiger Verdichtungen im Glaskörper stellt eine höhere, bei den Siuugetieren ebenfalls ausgesprochene Erscheinung dar. Sie lässt sich mit einiger Wahrscheinlichkeit mit einer funktionellen Differenzierung auf dem Gebiet der Säftezirkulation innerhalb des Glaskörpers in Zusammenhang bringen.

12. Die typische Anordnung der Glaskörperfibrillen bei den einzelnen Tieren lisst sich mit grosser Wahrscheinlichkeit auf statische Homente zurückführen, d. h. die stärkeren Fasersysteme stellen Trajektorien dar, in Beziehung stehend zu dem Innendruck des Auges und zu den auf das Auge von aussen einwirkenden Kirriften. 
360 Albert Szent-Györgyi: Der Glaskörper der Amphibien etc.

\section{Erklärung der Abbildungen auf Tafel XIV-XVIII.}

Sämtliche Zeichnangen sind mit Benützung des Zeichenapparates hergestellt. Die Vergrösserung ist etwas verschieden, daher die verschieden grossen Augen ungefähr die gleichen Maße aufweisen. Die Seite, nach der die Eintrittsstelle des Sehnerven verschoben ist, ist stets die temporale. Sämtliche Zeichnungen stellen Horizontalschnitte des Auges dar, mit schwacher Vergrösserung betrachtet, die Einzelheiten des Glaskörpers aber teilweise mit starker Vergrösserung hineingezeichnet.

Taf. XIV. Salamandra maculosa.

Taf. XV. Rana esculenta.

Taf. XVI. Tropidonotus natrix.

Taf. XVII. Lacerta viridis.

Taf. XVIII. Testudo graeca. 


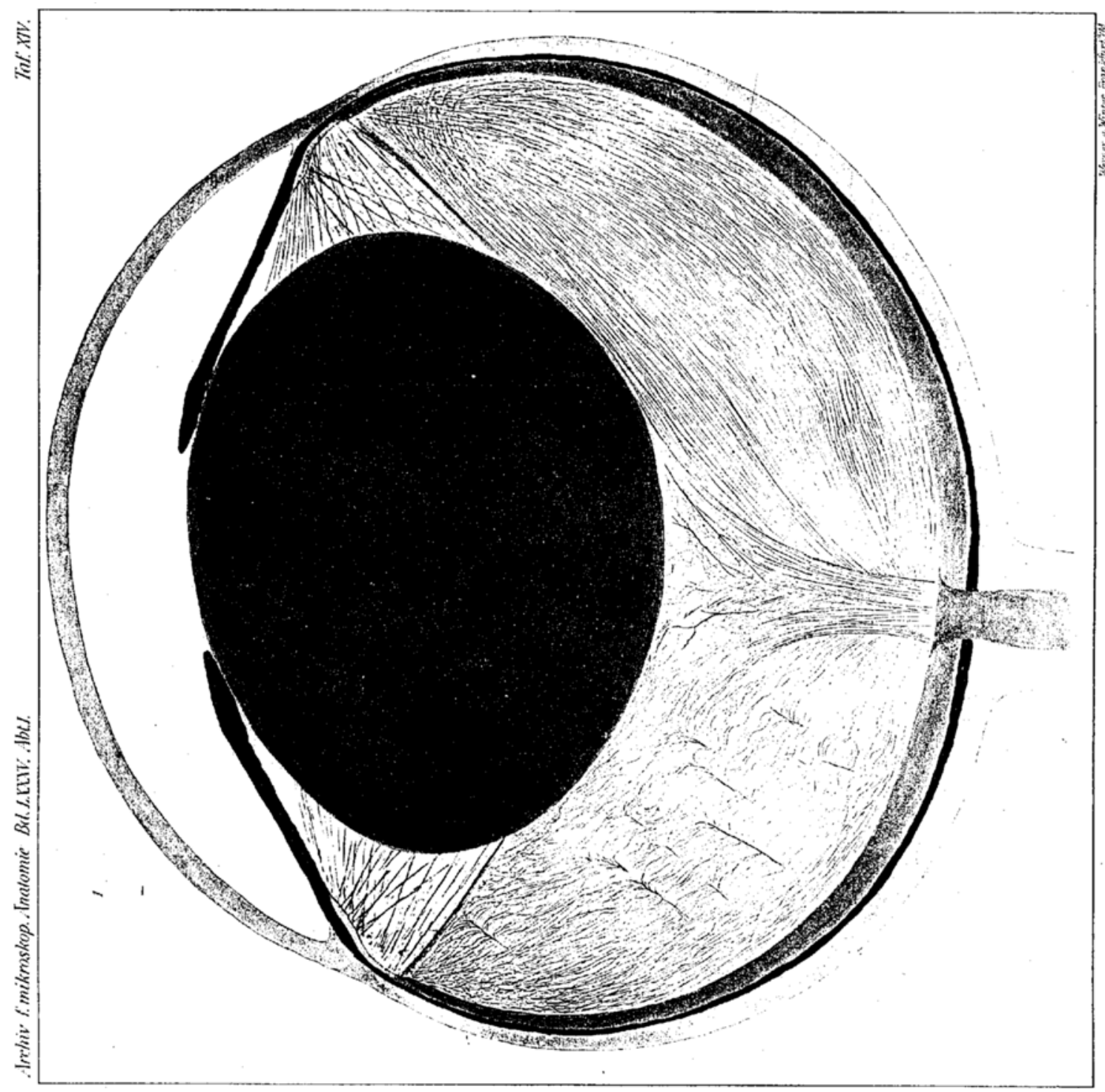




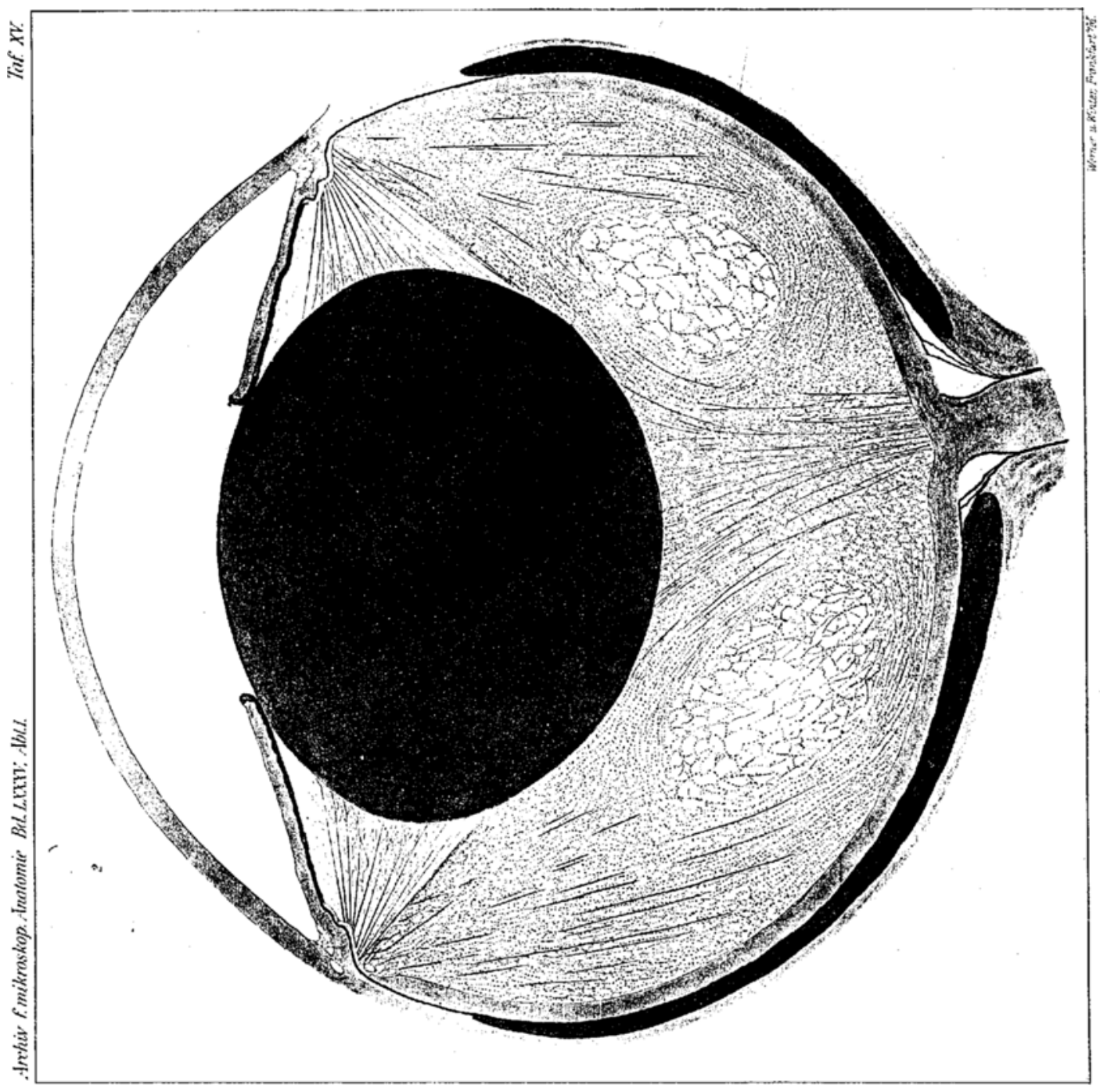




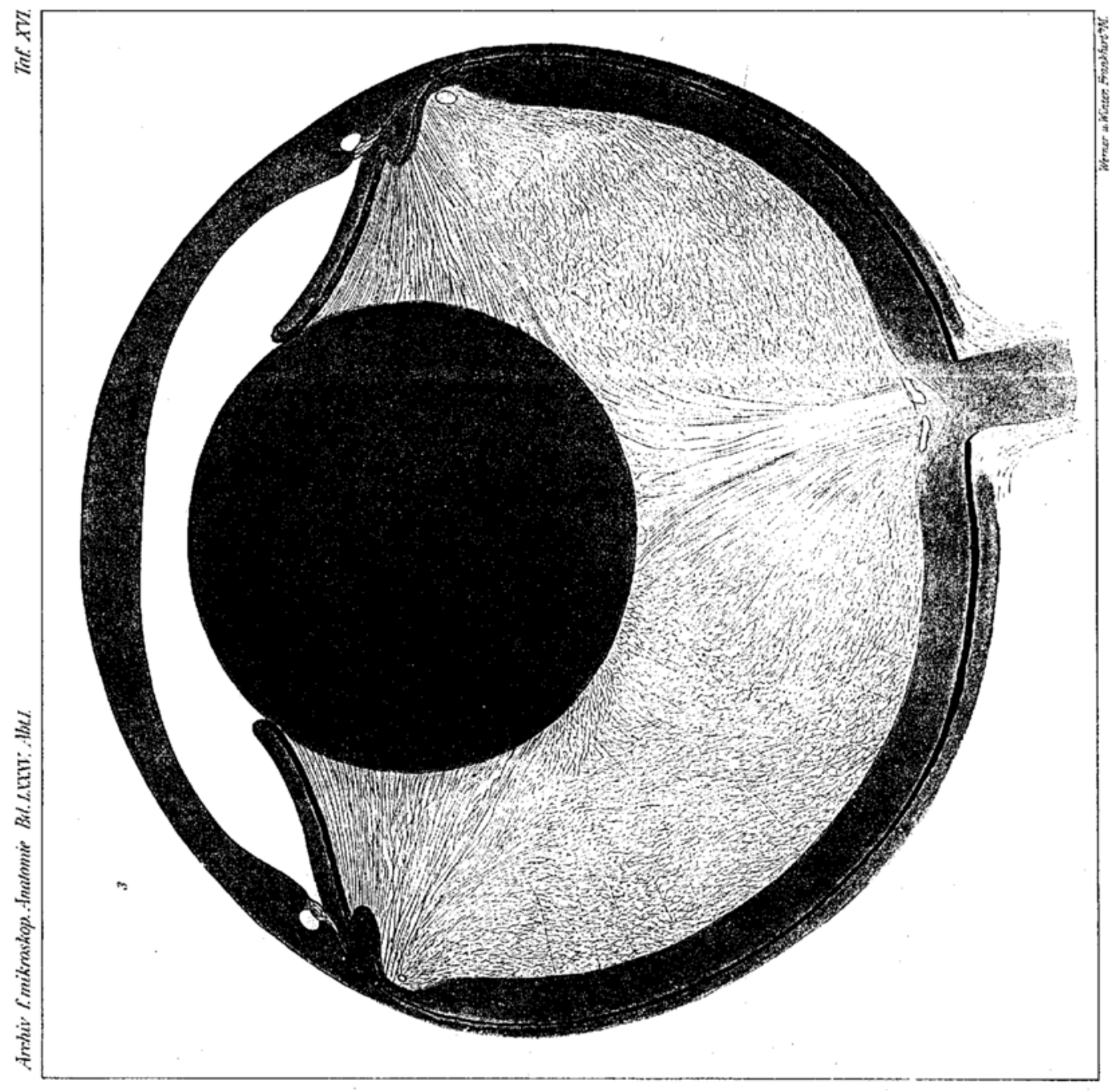




$$
\theta
$$




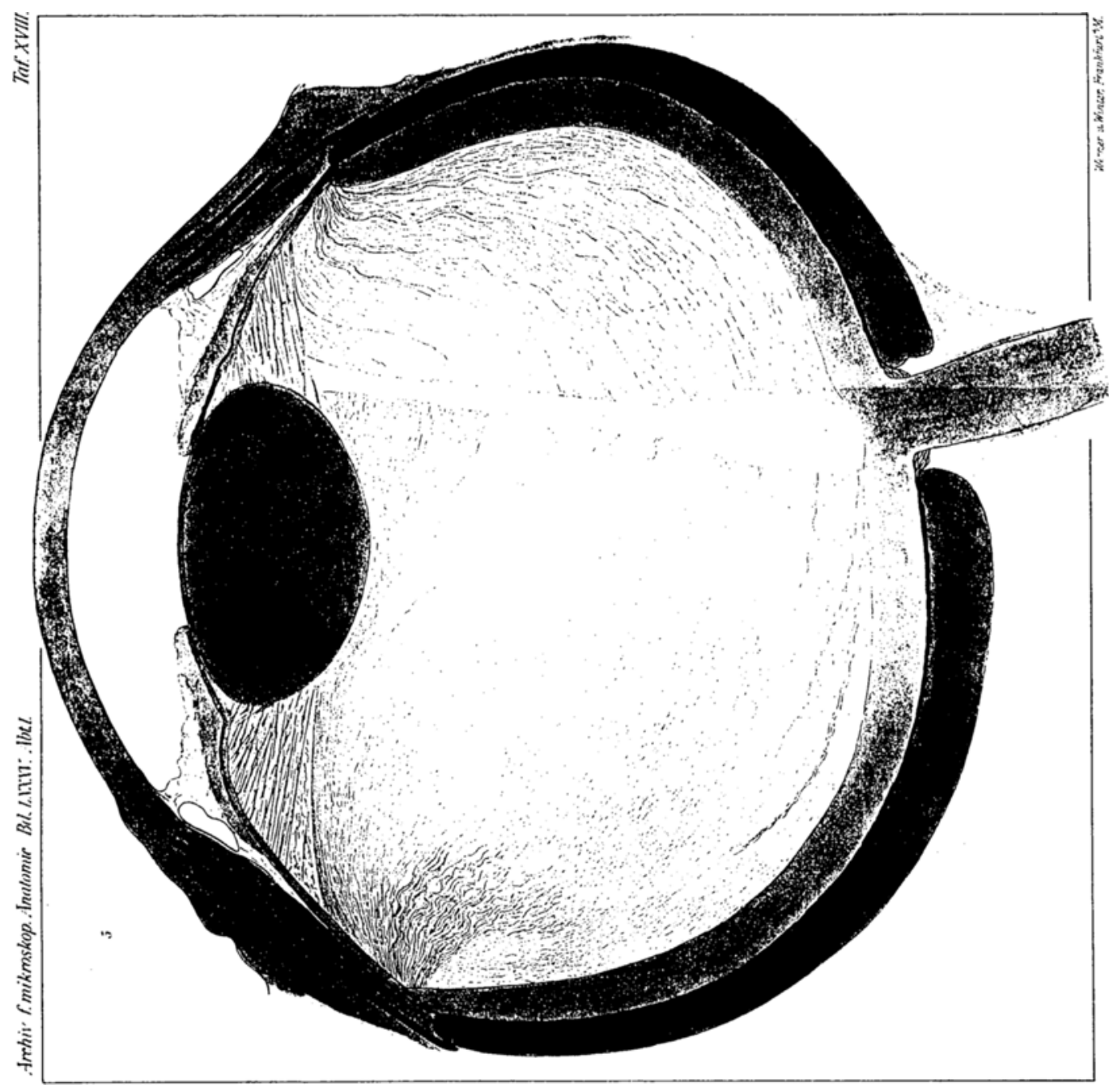

